Please do not remove this page

RMIT

UNIVERSITY

\title{
Properties of hydrophobically modified polyacrylamide with low molecular weight and interaction with surfactant in aqueous solution
}

Wu, Shu; Shanks, Robert; Bryant, Gary

https://researchrepository.rmit.edu.au/esploro/outputs/9921859414701341/filesAndLinks?institution=61RMIT_INST\&index=null

Wu, S., Shanks, R., \& Bryant, G. (2006). Properties of hydrophobically modified polyacrylamide with low molecular weight and interaction with surfactant in aqueous solution. Journal of Applied Polymer Science, 100(6), 4348-4360. https://doi.org/10.1002/app.23282

Document Version: Accepted Manuscript

Published Version: https://doi.org/10.1002/app.23282

Repository homepage: https://researchrepository.rmit.edu.au

(c) 2006 Wiley Periodicals, Inc

Downloaded On 2023/04/26 12:30:08 +1000

Please do not remove this page 
Thank you for downloading this document from the RMIT Research Repository.

The RMIT Research Repository is an open access database showcasing the research outputs of RMIT University researchers.

RMIT Research Repository: http://researchbank.rmit.edu.aul

\begin{abstract}
Citation:
Wu, S, Shanks, R and Bryant, G 2006, 'Properties of hydrophobically modified polyacrylamide with low molecular weight and interaction with surfactant in aqueous solution', Journal of Applied Polymer Science, vol. 100, no. 6, pp. 4348-4360.
\end{abstract}

See this record in the RMIT Research Repository at:

https://researchbank.rmit.edu.au/view/rmit:1246

Version: Accepted Manuscript

Copyright Statement:

(C) 2006 Wiley Periodicals, Inc

Link to Published Version:

http://dx.doi.org/10.1002/app.23282 


\title{
Properties of Hydrophobically Modified Polyacrylamide
}

\section{with Low Molecular Weight and Interaction with Surfactant in Aqueous Solution}

\author{
Shuhui Wu, Robert A. Shanks* and Gary Bryant \\ Applied Science, RMIT University \\ GPO Box 2476V, Melbourne, 3001, Australia \\ Journal of Applied Polymer Science, Vol. 100, 4348 - 4360 (2006) \\ Received 3 March 2005; accepted 22 September 2005 \\ DOI 10.1002/app.23282
}

Version date: 10 February 2004

Journal: Macromolecular Chemistry Physics

* Author for correspondence 


\begin{abstract}
Hydrophobically modified polyacrylamide (HMPAM), with a molecular weight of $10^{4}$ g/mol, was studied using a range of rheological methods and dynamic light scattering (DLS). DLS measurements indicate that the association of the modified polymer begins at low concentration. The modified polymer with high substitution forms transient networks below the critical concentration, but the networks are disrupted by the micelles formed by the polymer itself, and the networks do not contribute to viscosity enhancement. The modified polymers exhibited surface activity, so they may be regarded as non-ionic polymeric surfactants rather than thickeners. On the other hand, HMPAM is shown to interact with the surfactant SDS while PAM is inert to SDS. In the hydrophobic domains, it undergoes a surfactant-induced association process; in the hydrophobe-surfactant transition regions, the surfactant binds to the polymer in a non-cooperative way, and forms a polymer-surfactant complex. Contracted polymer chains begin to extend due to electrostatic repulsion, which can overcome the association at surfactant domains. The conformation of HMPAM polymer chains could be controlled by adding a certain amount of surfactant.
\end{abstract}

\title{
Key Words
}

Association; micelles; rheology; dynamic light scattering; solution properties; surfactant 


\section{Introduction}

Associative polymers are hydrophilic polymers modified with one or more hydrophobic groups. They have wide application in paints, foods, pharmaceutical products and in enhanced oil recovery. The hydrophobic groups can associate to minimize their exposure to water, and eventually a network is formed and the viscosity of the solution can increase dramatically. For these reasons, associative polymers can be used as thickeners.

There are two types of associative polymers. One type is the group of telechelic polymers, with hydrophobes located at the polymer chain terminal positions. An example is hydrophobic ethoxylated urethane (HEUR), which has molecular weight of the order of $10^{4}$ $\mathrm{g} / \mathrm{mol}$, and is prepared by the substitution method [1] [2] [3]. The other type is the comb-like polymers, with hydrophobes distributed randomly along the polymer backbone, such as hydrophobically modified alkali soluble emulsions (HASE) [4] [5] [6] and hydrophobically modified polyacrylamides (HMPAM) [7] [8] [9]. The molecular weight of these polymers is of the order of $10^{5}$ to $10^{6} \mathrm{~g} / \mathrm{mol}$, and the polymers are prepared by the co-polymerisation method. These two types of polymers have different association processes and rheological behaviour.

Another strictly alternating method was developed to synthesize comb-like polymers [10] [11] [12]. Using this method, comb-like copolymers can be prepared with a broad range of molecular weights, from $10^{4}$ to $10^{5} \mathrm{~g} / \mathrm{mol}$. This kind of polymer can be used to study the difference between comb-like polymers and telechelic polymers (with the same backbone and molecular weight), or the differences among comb-like polymers with different molecular weights. The rheological behaviour of associative polymers is very complicated, and is influenced by association type, molecular weight, backbone structure, hydrophobe structure and even spacer number [13]. 
Recently a new modification method has been developed in our laboratory. Using a simple substitution method, polyacrylamide (PAM) had been substituted with octyl and hexyl groups to form a comb-like hydrophobically modified polymer (HMPAM), without changing the backbone [14]. The modified comb-like polymer in this study has a molecular weight of $10^{4} \mathrm{~g} / \mathrm{mol}$, of the same order as telechelic polymers. The molecular weight is small compared with HMPAM prepared by co-polymerisation methods. The substituted groups, octyl and hexyl, are weak hydrophobes. For this reason, the properties of HMPAM in this study are different to that of other comb-like associative polymers prepared by copolymerisation methods. In this study, a combination of rheology, dynamic light scattering and surface chemistry methods were applied to characterise the distinctive properties and solution structure of the modified polymers, with particular emphasis on the rheological behaviour.

When the PAM hydrophilic backbone is modified with hydrophobic groups, the molecules become amphiphilic, and consequently become surface active. As the polymers studied have small molecular weights and an amphiphilic nature, they can be considered to be somewhere between a polymer and a surfactant. This behaviour is investigated here by studying the interaction between sodium dodecyl sulfate (SDS) and both PAM and HMPAM.

There are three classifications of polymer-surfactant interactions [15]. The first is the interaction of an ionic surfactant with a hydrophilic polyelectrolyte. If the polyelectrolyte has the opposite charge, phase separation may occur with one layer of surfactant micelle and one layer of the oppositely charged polymer. Or if the polyelectrolyte has the same charge, the ionic surfactant will have a screening effect on it. For this category, the interaction is purely electrostatic, and no hydrophobic interaction is involved. The second category is surfactant interaction with slightly hydrophobic polymers, where the hydrophobicity of the polymers is not enough for them to self-assemble. The important parameter for this interaction is the critical aggregation concentration (cac). At concentrations below the cac, there is no 
interaction; at concentrations above the cac, the surfactant micelles begin to bind to the polymer chains to form polymer-surfactant complexes, a process called polymer-induced micellarization. The third category is when the surfactant interacts with hydrophobically modified polymer (HMP), where the hydrophobes are strong enough to form micelles by themselves, and they have the capacity to solubilize the individual surfactant molecules, resulting in mixed micelle complexes. This category exhibits the strongest hydrophobic interaction.

The binding ratio of surfactant to polymer is defined as $\beta=C_{s, b} / C_{h}$, where $C_{s, b}$ is the concentration of bound surfactant and $C_{h}$ is the concentration of hydrophobes [15] [16] [17] [18] [19]. When the binding ratio is very small $(\beta<<1)$, there is no polymer-surfactant interaction, there are only pure HMP micelles in the solution, and the polymer behaviour is independent of surfactant concentration. When $\beta>1$, cooperative binding occurs. This occurs for the second polymer-surfactant interaction category, where the polymer is slightly hydrophobic. At low surfactant concentrations there is no binding, so $\beta$ is small; but as the concentration increases past the $c a c$, the value of $\beta$ increases dramatically. A closed association model is used to describe the cooperative binding, assuming that the bound micelle has a fixed aggregation number. When $\beta \sim 1$, the number of bound surfactant has the same order of the hydrophobes. For the third category of polymer-surfactant interaction, where polymer contains strongly hydrophobic groups, the polymer can bind individual surfactants, and it will saturate with surfactant in the same order of the hydrophobic sites, making the $\beta$ value close to 1 . This process is described as a non-cooperative process, and it is a continuous process, with the bound surfactant being always proportional to the number of hydrophobic sites, which is represented by a Langmuir isotherm model [20] [21]. 
With the surfactant concentration continuously increasing, the HMP-surfactant system goes from the hydrophobe domain, through a transition region into the surfactant domain. It follows a process of "hydrophobic species" in the system, starting from free hydrophobe sidechains, pure hydrophobe aggregates, mixed aggregates, free surfactant to pure surfactant aggregates. Free hydrophobe side-chains only exist at infinite dilute solution. Pure hydrophobe aggregates and pure surfactant aggregates exist in very large hydrophobes or surfactant domain regions. There are different binding isotherms in different regions. The most studied polymers are hydrophobically modified ethyl(hydroxyethyl)-cellulose ethers (HM-EHEC) or hydroxyethyl cellulose (HM-HEC) [18] [22] [23] [24] [25] [26] [27] [28] [29]. Unmodified EHEC or HEC have slight hydrophobicity, so the surfactant can bind to the polymer in a cooperative way above the cac. The corresponding HMP, on the other hand, has more complicated binding behaviour, which is believed to involve a two-step process. In the hydrophobe domains, the surfactant is bound to the polymer in a non-cooperative way, while the system contains pure hydrophobe aggregates and hydrophobe-dominated mixed micelles. In the transition region, the transitional mixed micelles exist in solution. Above the $c a c$, the surfactant starts to bind to the polymer in a cooperative way, complexes are formed, and the systems move into the surfactant domains. The mixture of mixed aggregates, free surfactant and pure surfactant aggregates coexist in this system. Other polymers, like non-ionic polyacrylamide (PAM), have very weak interaction with the surfactant SDS. The corresponding hydrophobically modified polymer, HMPAM, could absorb surfactant at hydrophobe sites in a non-cooperative way, until it is saturated [30] [31] [32] [33] [34] [35].

Phase behaviour is another important aspect of the study of the interaction of polymersurfactant systems. Phase studies have been reviewed exhaustively by Piculell, Lindman et al, in Lund University, Sweden, who pioneered this area [17][19][36][37]. In general, there are two types of phase separation: associative separation, where polymer and surfactant are 
enriched in the same phase; and segregative separation, where polymer and surfactant are separated into different phases [38]. It is believed that associative separation occurs when polymer-surfactant interactions dominate, while segregative separation occurs when polymersolvent interactions dominate. The phase behaviour of polymer-surfactant systems is very complicated, sometimes involving liquid crystalline, vesicle and other multi-component regions. Composite fractions, polymer and surfactant charge, hydrophilicity and temperature all influence the phase behaviour. While the Flory-Huggins theory is extensively used to describe it [39] [40].

Recently, new methodologies and instrumentation have developed rapidly, such as pulsed magnetic field gradient (PFG) NMR [18][30][41][42], light scattering [28][29][43] [44] [45], fluorescence [22][25][27][45] and neutron and X-ray scattering [46]. Meanwhile, other classical and fundamental methods like phase equilibrium, surface tension [30] [47], viscometry, are still used to study the interaction of polymers and surfactants, as these experiments are fast and readily available. In this paper, surface tension measurements and phase equilibrium are used to investigate the interaction between HMPAM and SDS.

\section{Experimental}

\section{Materials}

Polyacrylamide (PAM), as a $50 \mathrm{wt} \%$ aqueous solution with molecular weight of $10,000 \mathrm{~g} / \mathrm{mol}$ and density of $1.189 \mathrm{~g} / \mathrm{mL}$, was purchased from Aldrich Company. The solution was diluted to about $10 \%$ concentration, then lyophilised to obtain dry PAM solid. Sodium dodecylsulphate (SDS) was laboratory grade and used as received.

Hydrophobically modified PAM (HMPAM) was obtained by a transamidation method which has been described elsewhere [14]. Hexylamine (C6) and octylamine (C8) were used to 
modify the PAM. Substitution ratios were chosen as 1,3 or $5 \%$ (mole ratio) to PAM monomer units. The symbols for the modified polymers used are listed in Table 1.

\section{Solution / Emulsion Preparation}

SDS additives were dissolved in water with a variety of concentrations $(\mathrm{g} / \mathrm{L})$.

Dry PAM or HMPAM was dissolved in water or SDS aqueous solutions. Solution concentrations are expressed as a weight percentage of solid polymers (eg. $25 \mathrm{wt} \%$ refers to solute: solvent $=0.25: 0.75$ weight ratio).

Emulsions were prepared by mixing about $15 \mathrm{~mL}$ of polymer solution (concentration below $25 \mathrm{wt} \%$ ) and a few drops of decane. The mixture was placed on a shaker to shake for about 30 mins, then left overnight. Drops of liquid were studied under a microscope.

\section{Dilute Solution Viscosity Measurements}

An Ubbelohde viscometer was used to measure the relative viscosity of the solutions. The method and theory are described elsewhere. [48]

\section{Rheology of Concentrated Solutions}

Rheological properties of $50 \mathrm{wt} \%$ of PAM, C8_1, C8_3 and C8_5 solutions were measured using a Fluids Spectrometer II (RFS II) from Rheometrics Company, with a parallel plate measuring system. Silicone oil was placed at the edge of the two plates to prevent solvent evaporation. First, the dynamic strain sweep was measured at $1 \operatorname{rad}^{*} \mathrm{~s}^{-1}$ to determine the linear region. The storage modulus $G^{\prime}$ and loss modulus $G$ ', were measured over the frequency range $0.1 \sim 100 \mathrm{rad}^{*} \mathrm{~s}^{-1}$. Phase angles were also recorded. Strain amplitude of 0.2 was applied for all samples. For continuous shear measurement, the steady state viscosity $\eta$ was measured over the shear rate range of $0.1 \sim 100 \mathrm{~s}^{-1}$. 


\section{Dynamic Light Scattering (DLS)}

In Dynamic Light Scattering (DLS) a sample is illuminated by a laser beam, and the fluctuations in the scattered light, which are related to the motion of the particles, are measured. The theory is briefly outlined here. The fundamental quantity which is measured is the intensity autocorrelation function, $g^{(2)}(\tau)$, which is related to the normalized electric field autocorrelation function, $g^{(1)}(\tau)$, by:

$$
\mathrm{g}^{(2)}(\tau)=1+B\left|\mathrm{~g}^{(1)}(\tau)\right|^{2}
$$

where $B$ is an instrumental constant of order 1 . For a dilute, monodisperse suspension of non-interacting particles the electric field autocorrelation function is described by:

$$
\begin{aligned}
\left|\mathrm{g}^{(1)}(\tau)\right| & =\exp (-\Gamma \tau) \\
\Gamma & =\left(\frac{4 \pi n}{\lambda_{o}} \sin \left(\frac{\theta}{2}\right)\right)^{2} \mathrm{D}
\end{aligned}
$$

where $\Gamma$ is the decay constant of the fluctuations, $D$ is the particle diffusion coefficient, $n$ is the refractive index of the suspending liquid, $\theta$ is the scattering angle and $\lambda_{0}$ is the wavelength of the laser in vacuum.

For spherical particles the Stokes-Einstein relationship relates the diffusion constant D to the particle radius $\mathrm{r}$ :

$$
\mathrm{D}=\frac{\mathrm{k}_{\mathrm{B}} \mathrm{T}}{6 \pi \eta \mathrm{r}}
$$

Where $\mathrm{T}$ is the absolute temperature, $\mathrm{k}_{\mathrm{B}}$ is the Boltzmann constant and $\eta$ is the viscosity. 
DLS thus allows the determination of the hydrodynamic radius of the particles. If the sample contains two or more particle sizes, or more usually a distribution of particle sizes, then multi-component fits can be made to the data using a number of schemes.

Dynamic Light scattering (DLS) was performed using an ALV-compact goniometer. Samples were illuminated with a helium-neon laser with a wavelength of $633 \mathrm{~nm}$. Measurements were carried out at $25{ }^{\circ} \mathrm{C}$, and the scattering angle was set to $30^{\circ}$. Autocorrelation functions were measured using an ALV-5000 correlator card, and analysis was carried out using the inbuilt software. For the samples presented here, multi-exponential fits with 1, 2 or 3 components were used. The refractive index of solutions was measured using an ATAGO illuminator, Japan. The relative viscosity of the dilute solutions (under 25 wt $\%$ ) was measured using an Ubbelohde viscometer as described above, and the relative viscosity ratio was used to times the viscosity value of water. The absolutely viscosity of concentrated $50 \mathrm{wt} \%$ solutions was measured by the rheometer. Most of the samples were filtered prior to measurement using $0.8 \mu \mathrm{m}$ Millipore filters, in order to remove dust. Highly concentrated $50 \mathrm{wt} \%$ solutions were difficult to pass through the filter, and these were measured without filtration.

\section{Surface Tension Measurement}

The apparent surface tension was measured by the suspended drop method, using a Contact Angle System (OCA20), Particle and Surface Science Pty Ltd, at room temperature. Each sample was measured 5 times and the average was quoted as the result. For phaseseparated samples, the supernatant was measured. 


\section{Phase Equilibrium}

The turbidity of polymer-surfactant systems was determined by visual observation of the solution at room temperature, with the simple classifications of clear, turbid or phaseseparated.

\section{Optical Microscopy}

A Nikon Labophot II microscope was used to study the emulsion and the phase separated solutions. A few drops of liquid were gently placed in the well of a glass slide, which was placed under the microscope for observation. Dye was mixed with the liquid to increase image contrast. Images were captured using a Sony video camera connected to a Macintosh computer with IPLab image analysis software.

\section{Results and Discussion}

\section{Dilute Solution Viscosity}

Table 2 summaries the results of Ubbelohde viscometer measurements. The intrinsic viscosity $[\eta](\mathrm{dL} / \mathrm{g})$ of the modified polymers is almost identical to that of PAM. Normally the intrinsic viscosity of a modified polymer is lower than that of its unmodified analogue because of intramolecular interactions in dilute regions. The results here, however, show similar values for the different samples (the slightly higher value of HMPAM may due to excess hydrophobes). The PAM used in this experiment has low molecular weight, of the order of $10^{4} \mathrm{~g} / \mathrm{mol}$. Other HMPAM, prepared by micellar copolymerisation methods, can have molecular weights up to $10^{6} \mathrm{~g} / \mathrm{mol}$. The molecular weight of the monomer unit of PAM is $71 \mathrm{~g} / \mathrm{mol}$. For a polymer with $10000 \mathrm{~g} / \mathrm{mol} \mathrm{molecular}$ weight, the average polymerisation degree is 141 . Modified polymers with $1 \%$ substitution can only have one or two hydrophobes on each polymer chain, so only inter-molecular associations can occur. On the other hand, since the polymer chains are short, modified polymers with high substitution ratio 
have high rigidity, which makes the chains difficult to bend to form intramolecular associations. As the intrinsic viscosity is related to the effective hydrodynamic volume of the molecules in solution, the results indicate that a stiff polymeric backbone produces a similar hydrodynamic volume to that of the unmodified polymer.

The Huggins constants of the modified polymers (shown in Table 2) are lower than that of PAM, which indicates a better polymer-solvent interaction [48]. Due to the presence of hydrophobes in aqueous solution, the Huggins constant of a modified polymer is expected to be higher than that of its unmodified analogue. However, the trend is reversed here and the reason is not clear. A similar reversed trend has also been observed in unmodified / modified methacrylic acid - ethyl acrylate copolymer systems. An explanation was that the blocky ethyl acrylate segments in the polymer backbone were able to self-aggregate to reduce the total hydrophobic domain sites. [49]

The critical concentration $C^{*}$ of PAM, calculated as the reciprocal of intrinsic viscosity, was below $10 \mathrm{~g} / \mathrm{dL}$ (about $10 \mathrm{wt} \%$ ). Figure 1 shows the PAM concentration (wt\%) versus relative viscosity ratio. The curve shows that $C^{*}$ is between $15 \mathrm{wt} \%$ and $20 \mathrm{wt} \%$, which is higher than the calculated value.

\section{Rheology of Concentrated Solutions}

Figure 2 shows the steady viscosity of polymer solutions (50 wt\%) versus the shear rate. The figure shows that the viscosity of $\mathrm{C} 8 \_1$ and $\mathrm{C} 8 \_3$ is even lower than PAM, while C8_5 is slightly higher than that of PAM. Even though there are slight differences, the viscosities are of the same order. For other hydrophobically modified systems, the viscosity of the modified polymer can be a few orders higher than that of the unmodified polymer in the semi-dilute region.

Figure 3 shows the dynamic shear modulus versus shear rate for each of the polymers at a concentration of $50 \mathrm{wt} \%$. The $\mathrm{C} 8 \_1$ sample has the lowest $G^{\prime}$ and $G$ ', while C8_3 is 
almost the same as PAM, and both $G^{\prime}$ and $G^{\prime \prime}$ of C8_5 are slightly higher than that of PAM. All the values are of the same order, indicating that the modified polymers do not have significant viscosity enhancement. Table 3 summaries the exponents of power law fits for the four different samples. Exponents of $G^{\prime}$ are very small, and the exponents of $G^{\prime \prime}$ are in the order of $\mathrm{C} 8 \_5>\mathrm{PAM}>\mathrm{C} 8 \_3>\mathrm{C} 8 \_1$, close to 2 . Table 3 indicates that all four solutions are viscous liquids. Figure 4 shows the phase angle of the samples. C8_1 has the highest phase angle though the other three are similar. The dynamic result is well correlated with the steady state result in Figure 2. Combining the results from Figure 2 to Figure 4, sample C8_1 shows the most "liquid-like" properties and C8_5 the least. However, there is no significant change after modification.

The aim of the modification is to improve the viscosity / dynamic modulus, and obtain thickener behaviour. However, in this case thickening behaviour is not seen. The interpretation of this behaviour is as follows. There are two types of hydrophobic modified polymers: telechelic, with hydrophobes at terminal positions, molecular weights of order $10^{4}$ $\mathrm{g} / \mathrm{mol}$, such as HEUR; and comb-like polymers, with the hydrophobes distributed randomly along the backbone, molecular weights in the range $10^{5}$ to $10^{6} \mathrm{~g} / \mathrm{mol}$, such as HASE and HMPAM (prepared by co-polymerisation method). For telechelic polymers with low molecular weight entanglement is usually ignored, while a Rouse-like relaxation process is observed, and the chain relaxes independently [2]. For comb-like polymers, which have high molecular weight, chains become entangled in the semi-dilute region, while a hindered reptation relaxation process is observed, with chains disengaging from association junctions first, followed by a reptation process. Chain entanglement and hydrophobic association are believed to co-contribute to viscosity enhancement [6] [9][50][51]. The modified polymers studied here are comb-like polymers, but with low molecular weights only of $10^{4} \mathrm{~g} / \mathrm{mol}$. The 
dynamic modulus showed that $G^{\prime}$ was two orders lower than $G^{\prime \prime}$, the effect of entanglement can be ignored, therefore only hydrophobic association can improve the viscosity.

Groot and Agterroff used a "bead-spring" model to simulate the viscoelastic properties of common comb-like polymers [52]. The beads had binary associations, either free or paired. Because of entanglement, dissociation of individual associations did not break the connectivity of the networks, and the normal comb-like associative polymer had a broad relaxation time distribution [53]. Only bridge structures (hydrophobes in the same polymer chains distributed in different micelles) could support stress [2]. Lack of entanglement of polymers in the present study provides many fewer opportunities for hydrophobes in the same chain to enter different micelles and form bridge structures. Low molecular weights can lead to a broad range of dilute regions, and polymer chains cannot interact properly below $C^{*}$. It is well known that thickener behaviour is obtained in semi-dilute regions. The modified polymers studied here have similar viscosities to PAM at concentrations up to $50 \mathrm{wt} \%$, and a network is not formed sufficiently to increase the viscosity in these systems. The low molecular weight is therefore the key reason for the lack of significant rheological differences between the polymers.

The modified polymers can be dissolved in water even at concentrations as high as 50 wt $\%$. Although the viscosity and dynamic shear modulus do not change significantly, the modified polymers can self-assemble because of their amphiphilic structure (this was confirmed by dynamic light scattering and surface tension measurement). A number of polymer chains form single flower-like micelles. Semenow's model predicted a two-phase solution composed of close-packed micelles and a polymer-lean solvent phase [54]. Interaction of micelles contains two terms: one is a bridging attraction and the other is osmotic repulsion. The bridging attraction can lead to phase separation when the polymer cannot interact properly with the solvent. On the other hand, osmotic repulsion can lead to 
dispersion of polymers in solution. Heitz, Prud'homme and co-workers used an alternative strategy to synthesize comb-like associative polymers with the same backbone and modification ratio, but with different molecular weights. They found that phase separation occurred for the high molecular weight polymer while the lower one did not separate [11] [12]. The authors debated that the bridging between micelles was only favoured when the length of the polymer chain was too long for one micelle to accommodate an entire polymer chain. If a polymer chain contained hydrophobes more than the aggregation number of a micelle, phase separation could occur. The aggregation number of micelles in our systems was not studied, but it may be the in order of $20 \sim 50$ according to other results [11][45] [55] [56] [57]. The value is higher than the average number of hydrophobes in the highest substituted polymer C8_5 (about 7). Free chain ends extending into the solution provide a steric barrier which prevents bridging association. This explains why the modified polymer can still be dissolved at such high concentration (50 wt\%), while maintaining a similar viscosity to the unmodified PAM.

For the telechelic polymer HEUR, the situation is different. Viscoelastic properties of HEUR are sensitive to hydrophobe structure and functionality but not to polymer chain length. Thuresson et al [43] used mixtures of PEO diblock (DB) and triblock (TB) copolymers to study rheological properties. The DB was PEO with a hydrophobic tail on one end, which was a non-ionic surfactant. While the TB was PEO with hydrophobic tails on both ends, the same as HEUR. They found that only the TB contributed to formation of a transient network, while the connectivity was provided by bridging chains. For the DB, the copolymers could form large clusters of various size which were slightly interconnected to each other. The functionality of DB was not enough to form bridging chains (cross-linking junctions). The systems studied here are different, with hydrophobes distributed randomly along the backbone. Intramolecular association, analogous to the loop structure of a unimer in a 
telechelic polymer, does not contribute to viscosity improvement; while intermolecular association, not really an analogue to bridge structure, can lead to formation of clusters with larger size, but the large particle size does not imply efficient bridge structures. Only when the hydrophobes on the same chain join different micelles is it possible to form a network. Polymer chain entanglement can provide the opportunity to form an efficient network. Meanwhile, there is a balance between attractive and repulsive forces. When repulsion overcomes attraction, the viscosity of the solution can be increased while maintaining polymer dissolution. But when the attraction is larger than the repulsion, phase separation occurs and the rheological behaviour is suspension-like [58]. The modified polymers studied here have low molecular weight, resulting in lack of entanglement even at high concentration. There are far fewer opportunities for the polymers to form bridge structures, while viscosity cannot be improved significantly. In contrast, the repulsion of polymer clusters is large enough to maintain polymer dissolution. Further experiments need to be carried out systematically on the influence of molecular weight. Regaladao and co-workers [9] studied the rheology of HMPAM (prepared by co-polymerisation), and found molecular weight was a important parameter at very high concentration. However, the results obtained here suggest that, for comb-like polymers, there may be a critical molecular weight after which viscosity enhancement can occur.

\section{Dynamic Light Scattering (DLS)}

Figure 5 is the autocorrelation function $g^{(2)}(t)$ of PAM and HMPAM at $50 \mathrm{wt} \%$. PAM decays at short delay times, while the three HMPAM decay at a much longer delay time. This indicates that networks are formed in the HMPAM solution, but not for the PAM, even at this high concentration. For PAM with molecular weight of $10^{4} \mathrm{~g} / \mathrm{mol}$, the particle size of a unimer is of order of $1 \sim 2 \mathrm{~nm}$. For comparison, the particle size of a non-associated HEUR, 
with molecular weight of $2 \times 10^{4} \mathrm{~g} / \mathrm{mol}$, is $4.2 \mathrm{~nm}$ [45]; and for a HASE unimer, with a molecular weight of $2.2 \times 10^{5} \mathrm{~g} / \mathrm{mol}$, it is about $20 \mathrm{~nm}$ [44].

Table 4 shows the hydrodynamic radii for the modified polymers at various concentrations. In some cases two-component-fits gave the best results, and in these cases the approximate percentage of smaller particles is shown in brackets. For each polymer the particle size is of the order of $100 \sim 200 \mathrm{~nm}$ at $5 \mathrm{wt} \%$ concentration, which indicates that tens of molecules associate. For polymer $\mathrm{C} 8$ _ 1 , the size of the particles does not change significantly until $25 \mathrm{wt} \%$, followed by an increase in the apparent size by an order of magnitude at $50 \mathrm{wt} \%$. In addition, there is no significant contribution from any second component over the whole concentration range. The situation for samples C8_3 and C8_5 was quite different. For C8_3 the particle size showed a large increase at $15 \mathrm{wt} \%$, and two components were needed to fit the data, indicating a bimodal size distribution. For C8_5 there was a similar increase at $10 \mathrm{wt} \%$. The very large particle size suggests that a transient network is formed, with C8_5 forming this network at a lower concentration and higher ratio. In both cases the concentrations where these networks formed were below $C^{*}$. And in both cases, when the concentration was increased by a further $5 \mathrm{wt} \%$, the size decreased to a value comparable with the C8_1 polymer. At a concentration of $50 \mathrm{wt} \%$, all three polymers appeared to form a network. Above $25 \mathrm{wt} \%$, in the semi-dilute region, the polymer chain interactions are well developed even without entanglement. The bridge fraction will increase with concentration until a network forms.

The values of the largest particle sizes $(2000 \sim 3000 \mathrm{~nm})$ are larger than the filter pore size. The interpretation is that the reversible association junctions were broken during filtration, and re-formed after passing through the filter [44]. 
The DLS analysis shows that the HMPAM in this study does associate even though there is no significant increase in viscosity. The particle size was quite consistent over the whole range of concentration. The questions that need to be answered are: why is there no significant change in viscosity even though a network is formed? And why do the particle sizes of C8_3 and C8_5 decrease again at high concentration? As Figure 1 showed, the critical concentration $C^{*}$ was between $15 \mathrm{wt} \%$ and $20 \mathrm{wt} \%$, and this value is higher than that for which $\mathrm{C} 8 \_3$ and $\mathrm{C} 8 \_5$ showed an increased particle size. Below $C^{*}$, the polymer chains cannot interact efficiently; the junctions of networks are very weak reversible associations instead of chemical bonds. In this situation, the system cannot support stress any more efficiently than the unmodified PAM.

Rheology and DLS reflect different aspects of the solution properties. DLS shows that association does occur in the modified polymer; while rheology shows that the association has not contributed to a significant viscosity enhancement as for other associative polymers. The association is caused by the amphiphilic nature of the molecules. Surfactants are also amphiphilic, and their molecules are associated to form micelles in aqueous solution, but they do not lead to viscosity increases. PEO diblock copolymer (DB) is a non-ionic surfactant, and studies of DB, triblock copolymer (TB) and their mixture showed that TB polymer played a crucial role in the establishment of a strong network at high concentration [43]. As previously discussed, C8_1 polymer only contains one or two hydrophobes per chain, which is analogous to $\mathrm{DB}$, and it therefore could not contribute to network formation even through it was associated. While C8_3 and C8_5 are analogous to TB, there are excess hydrophobes to form bridge structures. The data shows that $\mathrm{C} 8$ _ 5 is more efficient, as it forms a network at lower concentration and higher percentage compared with C8_3. At higher concentrations, the networks become re-dissolved in the micelles themselves, and the connectivity is disrupted. The values of the particle size (except where networks were forming) were consistent over the 
whole range of concentrations. After modification, the polymers have surfactant properties, and the molecules can self-assemble into micelles, with bridge structures forming below $C^{*}$ in polymers with a high substitution ratio, but then re-dissolving in the micelles themselves.

The viscoelastic properties of associative polymers are very sensitive to surfactants. The classicial behaviour of associative polymers and surfactant interactions is that there is a viscosity maximum at a critical surfactant concentration. Below this concentration, the apparent viscosity of the associative polymer-surfactant solution increases, because the surfactant increases the strength and number of associations; above the critical concentration, excess surfactant would dissolve the hydrophobes, and network connectivity would be disrupted. The viscosity can drop even below the level when surfactant is absent [26] [59] [60] [61]. The polymers studied here, had both surfactant properties and associative polymer properties. So, once the polymers associate, the particle size increases and this can lead to enhancement of viscosity. On the other hand, as the polymer behaves like a surfactant, it will prevent network formation, thus lowing the viscosity. The balance between these competing effects may explain why the total viscosity is of the same order as PAM.

\section{Surface Activity}

After being modified with hydrophobic groups, PAM changes from a purely hydrophilic polymer into an amphiphilic polymer, and becomes surface active. Figure 6 is a graph of the surface tension versus polymer concentration. The curve shows that PAM has no surface activity. For C6_1, the hydrophobes are not hydrophobic enough to form micelles, and the surface tension only decreased slightly. For octyl modified polymers, the surface activity increased with hydrophobe content, and the surface tension became constant at high polymer concentrations. Other evidence of surface activity was that the hydrophobically modified polymer could be used as an emulsifying agent between water and oil. When PAM, 
water and decane are mixed, they phase separate completely into two layers, with PAM remaining in the aqueous phase. But a mixture of HMPAM, water and decane formed an emulsion with an average oil droplet diameter of about $30 \mu \mathrm{m}$ (shown in Figure 7). Thus HMPAM could be regarded as a polymeric non-ionic surfactant rather than a viscosity thickening agent, where the hydrophilic head-groups of the surfactant are the polymer backbone.

\section{Interaction with SDS in Hydrophobe Domains}

Although PAM interacts with SDS very weakly, HMPAM can interact with SDS. The important parameter for the interaction is the ratio between surfactant and hyrophobes $\left(\mathrm{N}_{\mathrm{SDS}} / \mathrm{N}_{\mathrm{h}}\right)$. When $\mathrm{N}_{\mathrm{SDS}} / \mathrm{N}_{\mathrm{h}}$ is below 1, the SDS and HMP solution is located in the hydrophobe domain regions. The polymer concentration was from $5 \mathrm{wt} \%$ to $25 \mathrm{wt} \%$, while the SDS concentration was between 0.5 and $2.5 \mathrm{~g} / \mathrm{L}$, consistent with experiments in other domains.

After mixing with SDS, the surface tension of solutions decreased rapidly to about 24 $\sim 26 \mathrm{~mJ} / \mathrm{m}^{2}$. The pure polymer solution was clear, but some HMPAM-SDS solutions became turbid, or phase separated. Small crystal-like gel particles of about $0.2 \sim 0.3 \mathrm{~mm}$ in size appeared in the solution, which are shown in Figure 8. Phase separation has previously been observed by dilution of a HMP system at an intermediate SDS concentration [37][42]. Figure 9 shows how phase conditions changed with $\mathrm{N}_{\mathrm{SDS}} / \mathrm{N}_{\mathrm{h}}$ (below 1). In this figure, phase separation ranked as 200, a turbid solution ranked as 150 and a clear solution as 100 . Turbid solutions varied from very turbid to slightly turbid, although they had the same ranking. Figure 9 indicates that the solutions became turbid and phase-separated gradually when $\mathrm{N}_{\mathrm{SDS}} / \mathrm{N}_{\mathrm{h}}$ increased from 0.01 to close to 1 . Although the regions overlap, the trend is clear that the polymer chains become contracted when SDS was added, until finally precipitation 
occurs. The hydrophobes on the polymer chains are hydrophobic enough to solubilize individual surfactant in this surfactant-induced association process.

\section{Interaction with SDS in Transitional and Surfactant Domains}

The transitional domains refer to when the ratio of surfactant and hydrophobes is stoichiometric (the same order). The value of $\mathrm{N}_{\mathrm{SDS}} / \mathrm{N}_{\mathrm{h}}$ was $1 \sim 4$. Surfactant domain regions refer to $\mathrm{N}_{\mathrm{SDS}} / \mathrm{N}_{\mathrm{h}}$ values over 4 . For these experiments the polymer concentration was chosen in the dilute region, $1 \mathrm{wt} \%$ and $2 \mathrm{wt} \%$, and SDS concentration started from $0.5 \mathrm{~g} / \mathrm{L}$.

Figure 10 is a graph of surface tension versus SDS concentration for the polymer solutions. It shows that the surface tension decreases rapidly on adding small amounts of SDS (see hydrophobe domains), followed by a minimum then the surface tension began to increase on further addition of surfactant. There are four solutions in the figure, $1 \mathrm{wt} \% \mathrm{C} 8 \_1$ (C8_1_1\%) and C8_3 (C8_3_1\%) solution, $2 \mathrm{wt} \% \mathrm{C} 8 \_3\left(\mathrm{C} 8 \_3 \_2 \%\right)$ and C8_5 (C8_5_2\%). The number of hydrophobe sites in C8_3_1\%, C8_3_2\% and C8_5_2\% solution were respectively 3, 6 and 10 times that of the C8_1_1\% solution. The range of minimum surface tension was increased with the increase in the number of hydrophobe sites. Figure 11 is a graph of the phase condition of solutions versus SDS concentration. The ranking was the same as for Figure 9. Comparing Figure 10 with Figure 11, it is found that the surface tension decreasing region corresponds to the phase separation region. The minimum value region corresponds to the turbid situation, and the surface tension increasing region corresponds to the one-phase region. Phase-change processes always followed from clear, slightly turbid, very turbid, phase separation, very turbid, slightly turbid to clear, it was a continual transition.

Figures 12 and 13 show the data from Figure 10 and 11 plotted as functions of the parameter $\mathrm{N}_{\mathrm{SDS}} / \mathrm{N}_{\mathrm{h}}$. They show that when $\mathrm{N}_{\mathrm{SDS}} / \mathrm{N}_{\mathrm{h}}$ is below 1 (hydrophobe domains), the surface tension of the polymer solutions decreases rapidly, and the polymers began to precipitate (see hydrophobe domains section). When $\mathrm{N}_{\mathrm{SDS}} / \mathrm{N}_{\mathrm{h}}$ is between 1 and 3 , it was 
within the apparent surface tension minimum region and the solutions gradually became clear. When $\mathrm{N}_{\mathrm{SDS}} / \mathrm{N}_{\mathrm{h}}$ was above 3 , the surface tension began to increase and the solutions finally became one-phase clear solutions.

PAM interacts with SDS very weakly, so the phenomena described above are due to the hydrophobes. Hydrophobes interact with SDS in a non-cooperative way, which is a continuous process described by the Langmuir isotherm. It is proposed that the absorption is proportional to the number of nucleation sites-hydrophobes. Effing et al [32] used surfactants with aromatic rings to study the interaction between HMPAM and anionic surfactants, they found that HMPAM was saturated with a limited amount of surfactant. Below a certain amount of surfactant, the polymer-surfactant system was described by a two-site model, composed of free surfactant and surfactant-bound-polymer; above that amount of surfactant, the system was a three-site model with free surfactant, free surfactant micelles and surfactantsaturated copolymer. Other HMPAM, which were studied by pulse field gradient NMR and surface tension methods, only bound low amounts of SDS, about 1 3 SDS per hydrophobe [30]. Combined with the results obtained in this study, it is proposed that SDS and HMP form a complex with $\mathrm{N}_{\mathrm{SDS}} / \mathrm{N}_{\mathrm{h}}$ from 1 to 3 . In this region, the system experiences a minimum apparent surface tension, and the polymer chains contract by hydrophobic association.

Phase separation of dilute EHEC and HMEHEC at intermediate SDS concentrations was reported by Nilsson et al [42], who also observed small gel-like particles, and the solubility of HMEHEC-SDS complex was decreased in the non-cooperative region. A critical $\mathrm{N}_{\mathrm{SDS}} / \mathrm{N}_{\mathrm{h}}$ value was responsible for surfactant-mediated gelation of HMHEC-surfactant systems, which was attributed to micelle-like aggregation bridged with multiple polymer chains. While if a gel forms entirely from solution in semi-dilute regions, polymer chains may form a network, and the gel phase will not appear as small particles. There is a balance 
between the hydrophobic attractive interactions and the electrostatic repulsive forces. In current systems, firstly adding low amounts of SDS could increase the attractions, then adding more SDS could lead to repulsive forces being increased to overcome the attractions, resulting in the micelles being dissolved.

When $\mathrm{N}_{\mathrm{SDS}} / \mathrm{N}_{\mathrm{h}}$ was over 3 , the apparent surface tension began to increase and the solution was clear again. After the polymer was saturated with surfactant, these non-ionic HMPAM formed a polymer-SDS complex, which had an apparent polyelectrolyte character. The "necklace" model has been proposed for polymer-surfactant complexes [16], considering the polymer chain as a string and surfactant clusters as beads. The electrostatic repulsion expands the polymer chains, and surfactant clusters are evenly distributed along the backbone, with hydrophobes as nucleation sites. This molecular picture was represented by Bigges and co-workers [34].

The experiments were not continued to very high SDS concentrations. Some workers have proposed that phase separation could occur again [19]. Unlike at intermediate SDS concentrations, where associative phase separation occurs (complex formation), the second phase separation should be a segregative separation, which is composed of a mixed aggregation phase and an excess pure surfactant aggregation phase. Adding SDS can increase the preference for interaction either with polymer or water, the former promotes associative interaction, while the later promotes segregative separation. The general phase behaviour for non-ionic polymer-anionic surfactants consists of monophasic, biphasic association, monophasic and biphasic segregation processes.

\section{Questions about Polymer-Surfactant Interaction}

The hydrophobe domains range from $5 \mathrm{wt} \%$ to $25 \mathrm{wt} \%$, and are located in the dilute to semi-dilute regions; while in transitional regions and surfactant domains, the concentration of 
polymer was chosen as $1 \mathrm{wt} \%$ and $2 \mathrm{wt} \%$, totally in the dilute region. The behaviour of HMPSDS in hydrophobe domains may be different if it was performed at the same concentration as transitional regions and surfactant domains. Using hydrophobically modified (hydroxypropyl)guar, viscosity studies showed a very complicated behaviour of polymersurfactant interactions [62]. There were four regions identified: infinite polymer solutionsurfactant before critical concentration; low polymer solution - surfactant before critical concentration; infinite polymer solution - surfactant after critical concentration and low polymer solution - surfactant after critical concentration. Each was responsible for different behaviour. In the current study, the small molecular weight leads to a very broad dilute region, the hydrophobe domains are studied over a broad range from the dilute region to the semi-dilute region, while SDS concentration was consistent with that of transitional and surfactant domains.

Another question is what was the composition of the precipitate. Was it pure polymersurfactant complex or an aggregation of a few polymer chains? Or was it a mixture of complex and aggregation? NMR could be used to analyse the composition, but would be inconclusive.

The third question is that after re-dissolution, it is not clear why the surface tension began to increase. In hydrophobe domains, the surfactant induced the polymer to associate, the polymer chains compacted (in dilute concentration) or bridge attraction increased (in semi-dilute concentration), leading to phase separation. The surface tension maintained a minimum value when $\mathrm{N}_{\mathrm{SDS}} / \mathrm{N}_{\mathrm{h}}$ was between $1 \sim 3$, corresponding to the complex formation ratio. The small value of surface tension indicated the surface activity, the polymer chains were very compact, and more molecules were assembled at the air-liquid interface. Figure 12 showed that the surface tension of polymer with more hydrophobe sites was slightly higher. 
This may be due to a relatively lower excess of surfactant, which caused the polymer to have a lower screening effect, therefore the polymer chains were slightly more expanded. The questions posed here cannot however be answered by surface tension methods, so other techniques need to be applied to further study HMPAM.

\section{Conclusions}

From dilute solution viscosity measurements, it was found that the various HMPAM with molecular weights of $10000 \mathrm{~g} / \mathrm{mol}$, had molecular sizes that were identical at infinite concentration due to the stiffness of backbone.

Rheological study of PAM and HMPAM concentrated solutions showed that the modified polymers had the same order of steady viscosity and dynamic shear modulus as PAM. There was no significant viscosity enhancement of the modified polymer. Both PAM and HMPAM at $50 \mathrm{wt} \%$ are viscous solutions. Among three modified samples, C8_1 showed the most liquid-like behaviour. It is proposed that molecular weight is a critical factor for comb-like polymers to provide thickener behaviour.

Dynamic light scattering measurement showed that hydrophobically modified polymers associated from low concentrations. The particle size of C8_1 was consistent over the range of $5 \mathrm{wt} \%$ to $25 \mathrm{wt} \%$, which suggested that the molecules self-assemble at a certain aggregation number. While for samples C8_3 and C8_5, transient networks were formed at concentrations below $C^{*}$, though at higher concentrations these networks re-dissolved into micelles formed by the polymer itself and were consequently disrupted. C8_5 could form bridge-chains easier than C8_3, and it formed a network at lower concentration and higher fraction compared with C8_3. Over the whole range of concentration, a network was not established efficiently enough to result in viscosity enhancement. 
Surface tension measurements and the emulsifying agent behaviour of modified polymer showed that HMPAM was surface active, so HMPAM can be regard as a non-ionic polymeric surfactant rather than a thickener.

HMPAM could interact with the surfactant SDS. The ratio between surfactant and hydrophobes $\left(\mathrm{N}_{\mathrm{SDS}} / \mathrm{N}_{\mathrm{h}}\right)$ was an important parameter. In the hydrophobe domains, with $\mathrm{N}_{\mathrm{SDS}} / \mathrm{N}_{\mathrm{h}}<1$, the surface tension of the polymer-surfactant system decreased rapidly with increasing $\mathrm{N}_{\mathrm{SDS}} / \mathrm{N}_{\mathrm{h}}$, and the solution changed from clear to turbid then finally phase separated, indicating that polymer chains contracted on addition of surfactant. This was identified as a surfactant-induced association process.

At $\mathrm{N}_{\mathrm{SDS}} / \mathrm{N}_{\mathrm{h}}$ between $1 \sim 3$ or 4 , there was a hydrophobe-surfactant transition region, where the surface tension of the polymer-surfactant system had a minimum plateau, the total system was separated into two phases at $\mathrm{N}_{\mathrm{SDS}} / \mathrm{N}_{\mathrm{h}}$ of about 1 , and gradually the system became clear at $\mathrm{N}_{\mathrm{SDS}} / \mathrm{N}_{\mathrm{h}}$ of about 4 . In this region, the surfactant bound to polymer in a noncooperative way, surfactant and HMPAM formed a complex, until the hydrophobes were saturated with surfactant. The polymer chains were most contracted at $\mathrm{N}_{\mathrm{SDS}} / \mathrm{N}_{\mathrm{h}}$ of about 1 , and the chains expanded on adding surfactant. The "necklace" model was used to describe the complex; electrostatic repulsive force finally overcame the association and the solution became clear again.

At $\mathrm{N}_{\mathrm{SDS}} / \mathrm{N}_{\mathrm{h}}$ above 3 , the system became totally clear, and the surface tension began to increase on addition of surfactants, though the reason for this remains unclear.

In general, even though HMPAM itself can be regarded as a non-ionic surfactant, it showed typical polymeric behaviour when it interacted with surfactant. The polymer chains were firstly contracted on adding surfactant, and bound with surfactant to form a complex. Later the polymer chains became extended due to electrostatic repulsion overcoming 
association. Adding a certain amount of surfactant could control the conformation of the polymer chains.

\section{Acknowledgements}

One of us (Shuhui Wu) acknowledges Australian Government for providing a Postgraduate Research Scholarship. 


\section{References}

1. M. R. Tarng, J. P. Kaczmarsk, D. J. Lundberg, J. E. Glass, "Comparative Flow Properties of Model Associative Thickener Aqueous Solutions", in: Hydrophilic Polymers: Performance with Environmental Acceptance, J. E. Glass, Ed., American Chemical Society, Washington, 1996. p.305

2. T. Annable, R. Buscall, R. Ettelaie, D. Whittlestone, J. Rheol., 1993, 37, 695.

3. K. C. Tam, R. D. Jenkins, M. A. Winnik, D. R. Bassett, Macromol., 1998, 31, 4149.

4. R. D. Jenkins, L. M. DeLong, D. R. Bassett, "Influence of Alkali-Soluble Associative Emusion Polymer Architecture on Rheology", in: Hydrophilic Polymers: Performance with Environmental Acceptance, J. E. Glass, Ed., American Chemical Society, Washington, 1996. p.425

5. V. Tirtaatmadia, K. C. Tam, R. D. Jenkins, Macromol., 1997, 30, 3271.

6. R. J. English, H. S. Gulati, J. D. Jenkins, S. A. Khan, J. Rheol., 1997, 41, 427.

7. E. Volpert, J. Selb, F. Candau, Macromol., 1996, 29, 1452.

8. E. Volpert, J. Selb, F. Candau, Polym., 1998, 39, 1025.

9. E. J. Regalado, J. Selb, F. Candau, Macromol., 1999, 32, 8580.

10. B. Xu, L. Li, K. Zhang, P. M. Macdonald, M. A. Winnik, R. D. Jenkins, D. Bassett, D. Wolf, O. Nuyken, Langmuir, 1997, 13, 6896.

11. C. Heitz, S. Pendharkar, R. K. Prud'homme, J. Kohn, Macromol., 1999, 32, 6652. 
12. C. Heitz, R. K. Prud'homme, J. Kohn, Macromol., 1999, 32, 6658.

13. S. Wu, S. R. A. Shanks, "Rheology of hydrophobically Modified Polyacrylamide in Water", in: 19th Polymer Processing Society, Melbourne, 2003, 369)

14. S. Wu, R. A. Shanks. "Synthesis and Characterization of Hydrophobic Modified PAM", in: 19th Polymer Processing Society, Melbourne, 2003, 368)

15. P. Linse, L. Piculell, P. Hansen, "Model of Polymer-Surfactant Complexation", in: Polymer-Surfactant Systems, J. C. T. Kwak, Ed., Marcel Dekker, New York, 1998. p.193

16. K. Shirahama, "The Nature of Polymer-Surfactant Interactions", in: PolymerSurfactant Systems, J. C. T. Kwak, Ed., Marcel Dekker, New York, 1998. p.143

17. L. Piculell, F. Guillemet, K. Thuresson, V. Shubin, O. Ericsson, Advances in Colloid and Interface Science, 1996, 63, 1.

18. L. Piculell, S. Nilsson, J. Sjostrom, K. Thuresson, "How Much Surfactant Binds to an Associating Polymer? The HMHEC/SDS Case Revisited", in: Associative Polymer in Aqueous Media, J.E. Glass, Ed., American Chemical Society, Washington, 2000. p317

19. L. Piculell, K. Thruesson, B. Lindman, Polym. Adv.Technol., 2001, 12, 44.

20. D. F. Evans, H. Wennerstrom, in: The Colloidal Domain: Where Physics, Chemistry, Biology and Technology Meet. VCH Publishers, New York 1994, p. 66.

21. K. Thuresson, K. B. Lindman, J. Phys. Chem. B., 1997, 101, 6460. 
22. K. Thuresson, K., O. Soderman, P. Hansson, G. Wang, J. Phys. Chem., 1996, 100, 4909.

23. S. Nilsson, M. Goldraich, B. Lindman, Y. Talmon, Langmuir, 2000, 16, 6825.

24. K. Thuresson, S. Nilsson, B. Lindman, Langmuir, 1996, 12, 530.

25. S. Nilsson, K. Thuresson, P. Hansson, B. Lindman, J. Phys. Chem. B., 1998, 102, 7099.

26. R. Tanaka, J. Meadows, P. A. Williams, G. O. Phillipa, Macromol., 1992, 25, 1304.

27. H., Evertsson, S. Nilsson, C. Holmberg, L. O. Sundeloef, Langmuir, 1996, 12, 5781.

28. B. Nystrom, K. Thuresson, B. Lindman, Langmuir, 1995, 11, 1994.

29. K. Thuresson, B. Nystrom, B. Wang, B. Lindman, Langmuir, 1995, 11, 3730.

30. H. B. M. Kopperud, H. Walderhaug, F. K. Hansen, Macromol. Chem. Phys., 1999, $200,1839$.

31. H. B. M. Kopperud, F. K. Hansen, B. Nystrom, Macromol. Chem. Phys., 1998, 199, 2385.

32. J. J. Effing, I. J. McLennan, N. M. van Os, J. C. T. Kwak, J. Phys. Chem., 1994, 98, 12397.

33. J. J. Effing, I. J. McLennan, J. C. T. Kwak, J. Phys. Chem., 1994, 98, 2499.

34. S. Biggs, J. Selb, F. Candau, Langmuir, 1992, 8, 838.

35. C. Howley, D. G. Marangoni, J. C. T. Kwak, Colloid. Polym. Sci,, 1997, 275, 760. 
36. L. Piculell, B. Lindman, G. Karlstrom, "Phase Behavior of Polymer-Surfactant Systems", in: Polymer-Surfactant Systems, J. C. T. Kwak, Ed., Marcel Dekker, New York, 1998. p.65

37. K. Thuresson, K. F. Joabsson, Colloids and Surfaces: A, 1999, 151, 513.

38. L. Piculell, K. Bergfeldt, S. Gerdes, J. Phys. Chem., 1996, 100, 3675.

39. M. Tsianou, K. Thuresson, L. Piculell, Colloid. Polym. Sci., 2001, 279, 340.

40. K.-W. Zhang, G. Karlstrom, B. Lindman, Colloids and Surfaces, 1992, 67, 147.

41. K. Persson, G. Wang, G. Olofsson, J. Chem. Soc. Faraday. Trans., 1994, 90(23), 3555 .

42. S. Nilsson, K. Thuresson, B. Lindman, B. Nystrom, Macromol., 2000, 33, 9641.

43. K. Thuresson, S. Nilsson, A.-L. Kjoniksen, H. Walderhaug, B. Lindman, B. Nystrom, J. Phys. Chem. B., 1999, 103, 1425.

44. S. Dai, K. C. Tam, R. D. Jenkins, Macromol., 2000, 33, 404.

45. E. Alami, M. Almgren, W. Brown, J. Francois, Macromol., 1996, 29, 2229.

46. A. P. Rodenhiser, J. C. T. Kwak, "Polymer-Surfactant System: Introduction and Overview", in: Polymer-Surfactant Systems, J. C. T. Kwak, Ed., Marcel Dekker, New York, 1998. p.1

47. A. Haruhiko, M. Moriyasu, K. Shinoda, J. Colloid and Interface Sci., 1971, 37 (1), 223.

48. S. Wu, R. A. Shanks, J. Appli. Polym. Sci., 2003, 89, 3122. 
49. W. K. Ng, K.C. Tam, R.D. Jenkins, Polym., 2001, 42, 249.

50. R. J. English, R. D. Jenkins, D. R. Bassett, S. A. Khan, "Rheology of a HASE Associative Polymers and Its Interaction with Non-ionic Surfactant", in: Assoiative Polymers in Aqueous Media, J. E. Glass, Ed., American Chemical Society, Washington, 2000. p.369

51. R. J. English, J. H. Laurer, R. J. Spontak, S. A. Khan, Ind. Eng. Chem. Res., 2002, 41, 6425.

52. R. D. Groot, W. G. M. Agterof, Macromol., 1995, 28, 6284.

53. B. Xu, A. Yekta, M. A. Winnik, K. Sadeghy-Dalivand, D. F. James, R. D. Jenkins, D. R. Bassett, Langmuir, 1997, 13, 6903.

54. A. N. Semenov, J. F. Joanny, A. R. Khokhlov, Macromol., 1995, 28, 1066.

55. E. Kumacheva, Y. Rharbi, M. A. Winnik, L. Guo, K. C. Tam, R. D. Jenkins, Langmuir, 1997, 13, 182.

56. K. Horiuchi, K. Rharbi, J. G. Spiro, A. Yekta, M. A. Winnik, R. D. Jenkins, Langmuir, 1999, 15, 1644.

57. E. Araujo, Y. Kharbiy, X. Huang, M. A. Winnik, D. R. Bassett, R. D. Jenkins, Langmuir, 2000, 16, 8664.

58. S. A. Ezzell, C. L. McCormick, Macromol., 1992, 25, 1881.

59. T. Aubry, M. Moan, J. Rheol., 1996, 40 (3), 441.

60. W. P. Seng, K. C. Tam, R. D. Jenkins, Colloids and Surfaces: A, 1999, 154, 365. 
61. G. L. Smith, C. L. McCormick, Langmuir, 2001, 17, 1719.

62. T. Aubry, M. Moan, J. F. Argillier, A. Audibert, Macromol., 1998, 31, 9072. 


\section{List of Tables and Figures}

Table 1. Symbol of modified polymers.

Table 2 . The intrinsic viscosity $[\eta](\mathrm{dL} / \mathrm{g})$ and Huggins constant $k_{H}$ of polymers

Table 3. Exponents of power law for polymers

Table 4. Hydrodynamic radii $(\mathrm{nm})$ of HMPAM at various polymer concentration (wt\%). For the bimodal samples, the approximate percentage of particles is shown in brackets.

Figure 1. Relative viscosity ratio of PAM versus polymer concentration (wt\%)

Figure 2. Steady viscosity (Pa.s) of polymers $(50 \mathrm{wt} \%)$ versus shear rate $\left(\mathrm{s}^{-1}\right)$

Figure 3. Dynamic storage modulus $G^{\prime}(\mathrm{Pa})$ and loss modulus $G^{\prime \prime}(\mathrm{Pa})$ versus frequency $(\mathrm{rad} / \mathrm{s})$ for $50 \mathrm{wt} \%$ polymers

Figure 4. Phase angle of $50 \mathrm{wt} \%$ polymer solutions versus frequency $(\mathrm{rad} / \mathrm{s})$

Figure 5. Autocorrelation function $g^{(2)}(t)$ of polymers at $50 \mathrm{wt} \%$.

Figure 6. Surface tension $\left(\mathrm{mJ} / \mathrm{m}^{2}\right)$ versus polymer concentration $(\mathrm{wt} \%)$ in pure water solution

Figure 7. Photo of water-HMPAM-decane mixture (x100)

Figure 8. Photos of phase separation at HMPAM-SDS systems (x100)

Figure 9. Phase conditions of HMPAM-SDS systems versus value of $\mathrm{N}_{\mathrm{SDS}} / \mathrm{N}_{\mathrm{h}}(<1)$.

Figure 10. Surface tension $\left(\mathrm{mJ} / \mathrm{m}^{2}\right)$ of HMPAM-SDS systems versus SDS concentration $(\mathrm{g} / \mathrm{L})$

Figure 11. Phase conditions of HMPAM-SDS systems versus SDS concentration (g/L)

Figure 12. Surface tension $\left(\mathrm{mJ} / \mathrm{m}^{2}\right)$ of HMPAM-SDS systems versus value of $\mathrm{N}_{\mathrm{SDS}} / \mathrm{N}_{\mathrm{h}}(>1)$

Figure 13. Phase conditions of HMPAM-SDS systems versus value of $\mathrm{N}_{\mathrm{SDS}} / \mathrm{N}_{\mathrm{h}}(>1)$ 


\begin{tabular}{c||c|c}
\hline & Substitution Group & Substitution Ratio \\
\hline \hline PAM & - & $1 \%$ \\
\hline C6_1 & Hexyl & $1 \%$ \\
\hline C8_1 & Octyl & $3 \%$ \\
\hline C8_3 & Octyl & $5 \%$ \\
\hline C8_5 & Octyl & \\
\hline
\end{tabular}

Table 1. Symbol of modified polymers. 


\begin{tabular}{c|c|c}
\hline & {$[\eta](\mathrm{dL} / \mathrm{g})$} & $k_{H}$ \\
\hline PAM & 0.1101 & 0.99 \\
\hline C8_1 & 0.1125 & 0.92 \\
\hline C8_3 & 0.1328 & 0.6 \\
\hline C8_5 & 0.1293 & 0.66 \\
\hline
\end{tabular}

Table 2. The intrinsic viscosity [ $\eta]$ (dL/g) and Huggins constant $k_{H}$ of polymers 


\begin{tabular}{c|c|c}
\hline & $G^{\prime}$ & $G^{\prime}$ \\
\hline \hline PAM & 0.103 & 2.2 \\
\hline C8_1 & 0.051 & 1.44 \\
\hline C8_3 & 0.072 & 1.83 \\
\hline C8_5 & 0.107 & 2.35 \\
\hline
\end{tabular}

Table 3. Exponents of power law for polymers 


\begin{tabular}{c||c|c|c}
\hline & C8_1 & C8_3 & C8_5 \\
\hline \hline $5 \mathrm{wt} \%$ & 117 & 166 & $220 \sim 226$ \\
& & & $50 \sim 100(16 \%)$ \\
\hline $10 \mathrm{wt} \%$ & $129 \sim 142$ & $150 \sim 250$ & $\mathbf{2 0 0 0} \sim \mathbf{3 0 0 0}$ \\
& & $87(16 \%)$ & $130 \sim 170$ \\
\hline $15 \mathrm{wt} \%$ & $130 \sim 170$ & $\mathbf{2 0 0 0} \sim \mathbf{3 0 0 0}$ & $170 \sim 220$ \\
& & $96(52 \%)$ & $160 \sim 180$ \\
\hline $20 \mathrm{wt} \%$ & $140 \sim 240$ & $150 \sim 170$ & $\mathbf{6 0 0} \sim \mathbf{1 0 0 0}$ \\
\hline $25 \mathrm{wt} \%$ & $\mathbf{9 5 0} \sim \mathbf{1 6 0 0}$ & $\mathbf{6 8 0} \sim \mathbf{1 1 0 0}$ & \\
\hline $50 \mathrm{wt} \%$ & & & \\
\hline
\end{tabular}

Table 4. Hydrodynamic radii (nm) of HMPAM at various polymer concentration (wt\%). For the bimodal samples, the approximate percentage of particles is shown in brackets. 


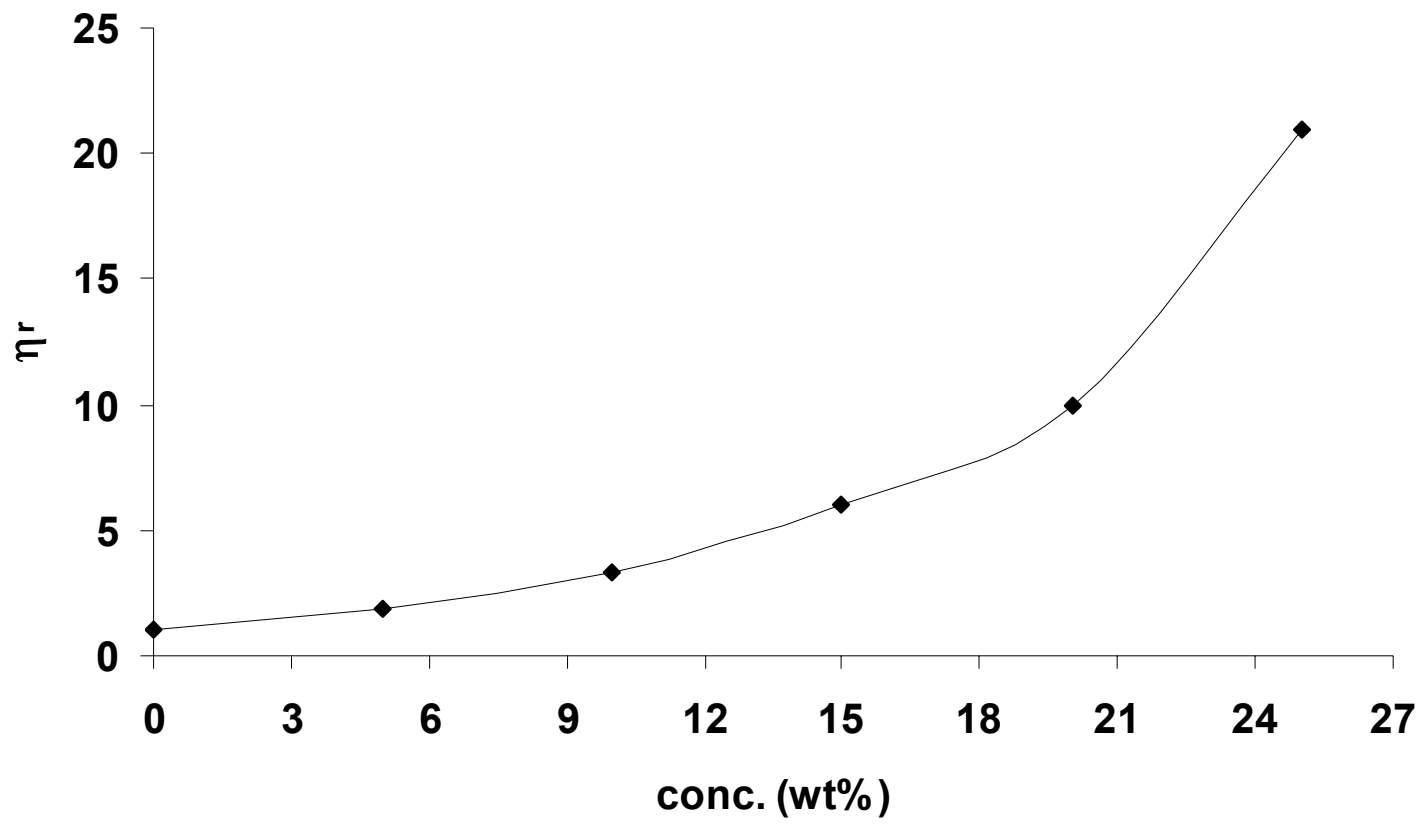

Figure 1. Relative viscosity ratio of PAM versus polymer concentration (wt $\%$ ) 


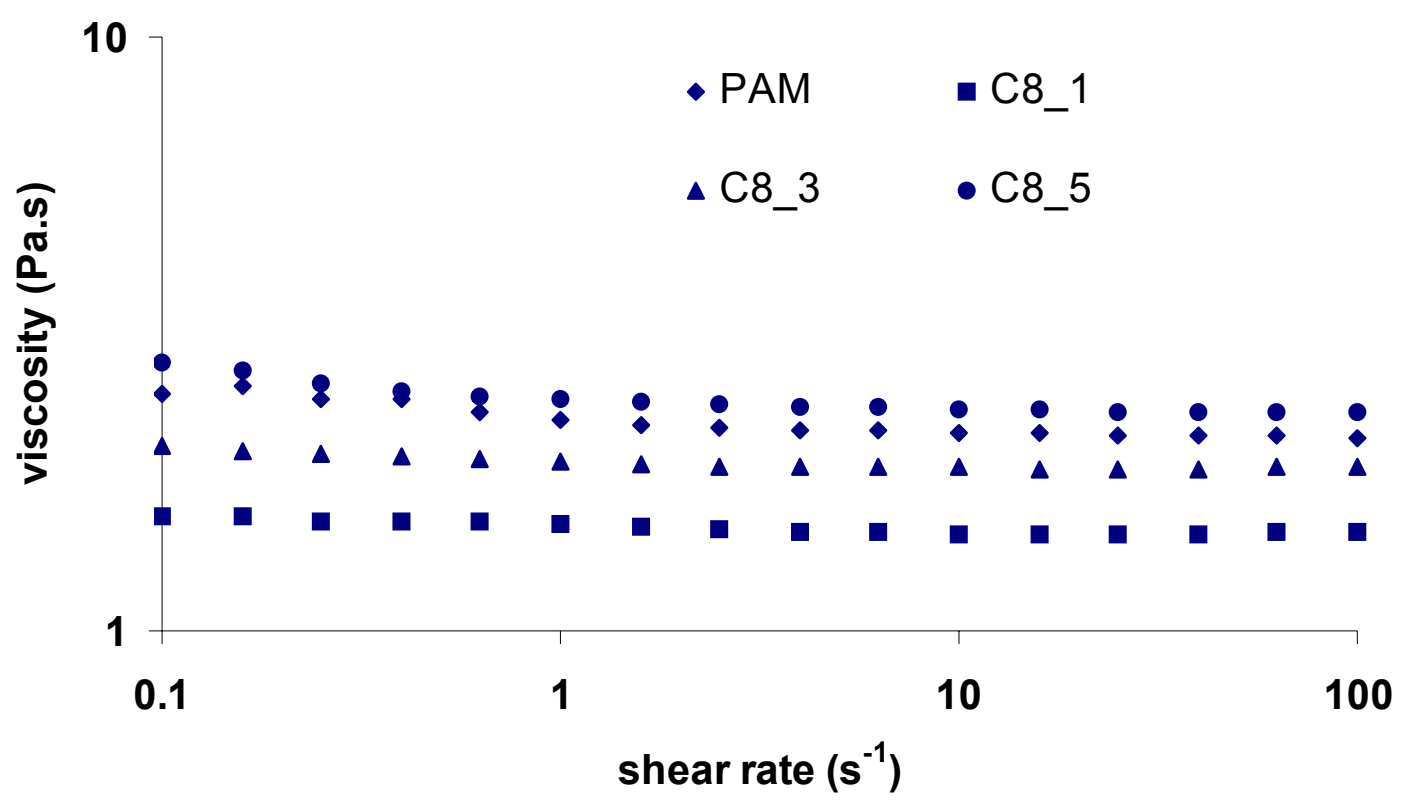

Figure 2. Steady viscosity (Pa.s) of polymers (50 wt $\%$ ) versus shear rate $\left(\mathrm{s}^{-1}\right)$ 


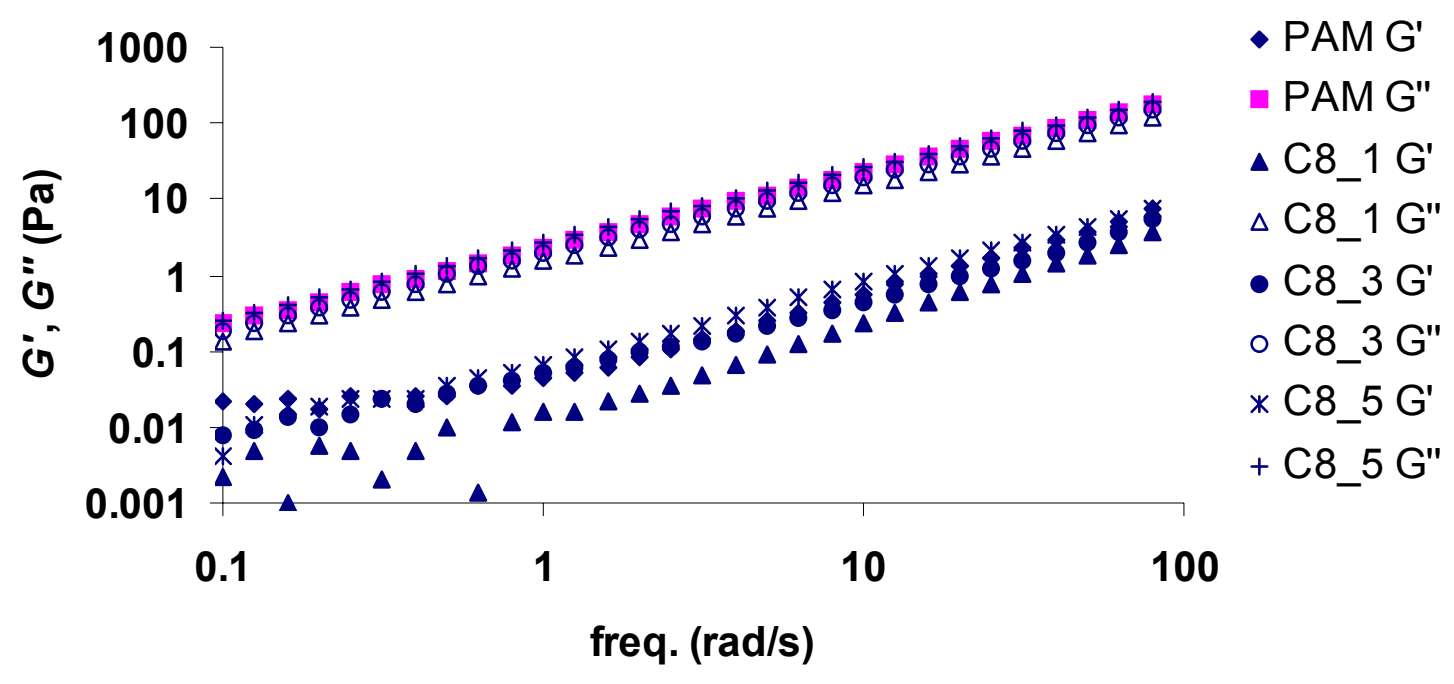

Figure 3. Dynamic storage modulus $G^{\prime}(\mathrm{Pa})$ and loss modulus $G^{\prime \prime}(\mathrm{Pa})$ versus frequency $(\mathrm{rad} / \mathrm{s})$ for $50 \mathrm{wt} \%$ polymers 


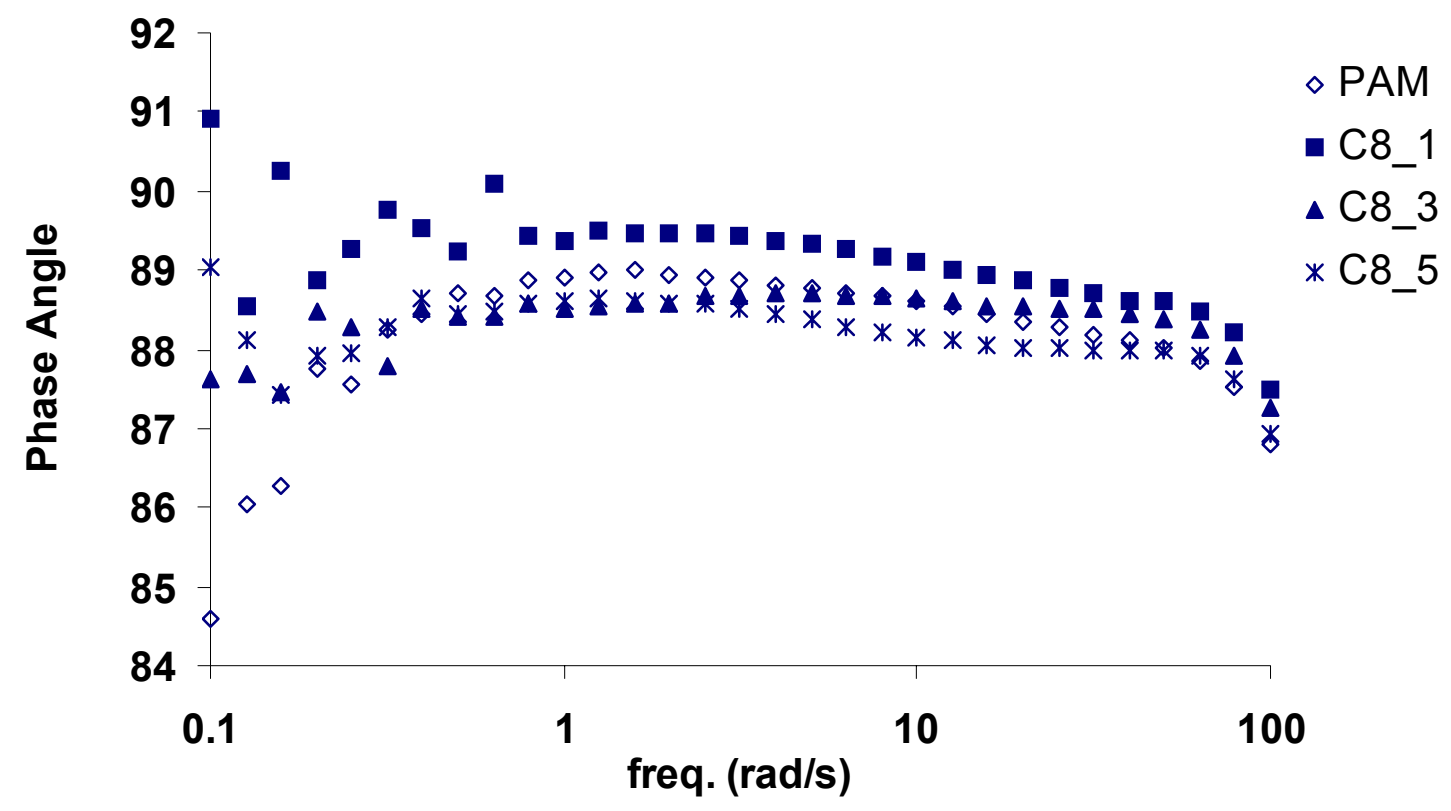

Figure 4 . Phase angle of $50 \mathrm{wt} \%$ polymer solutions versus frequency $(\mathrm{rad} / \mathrm{s})$ 


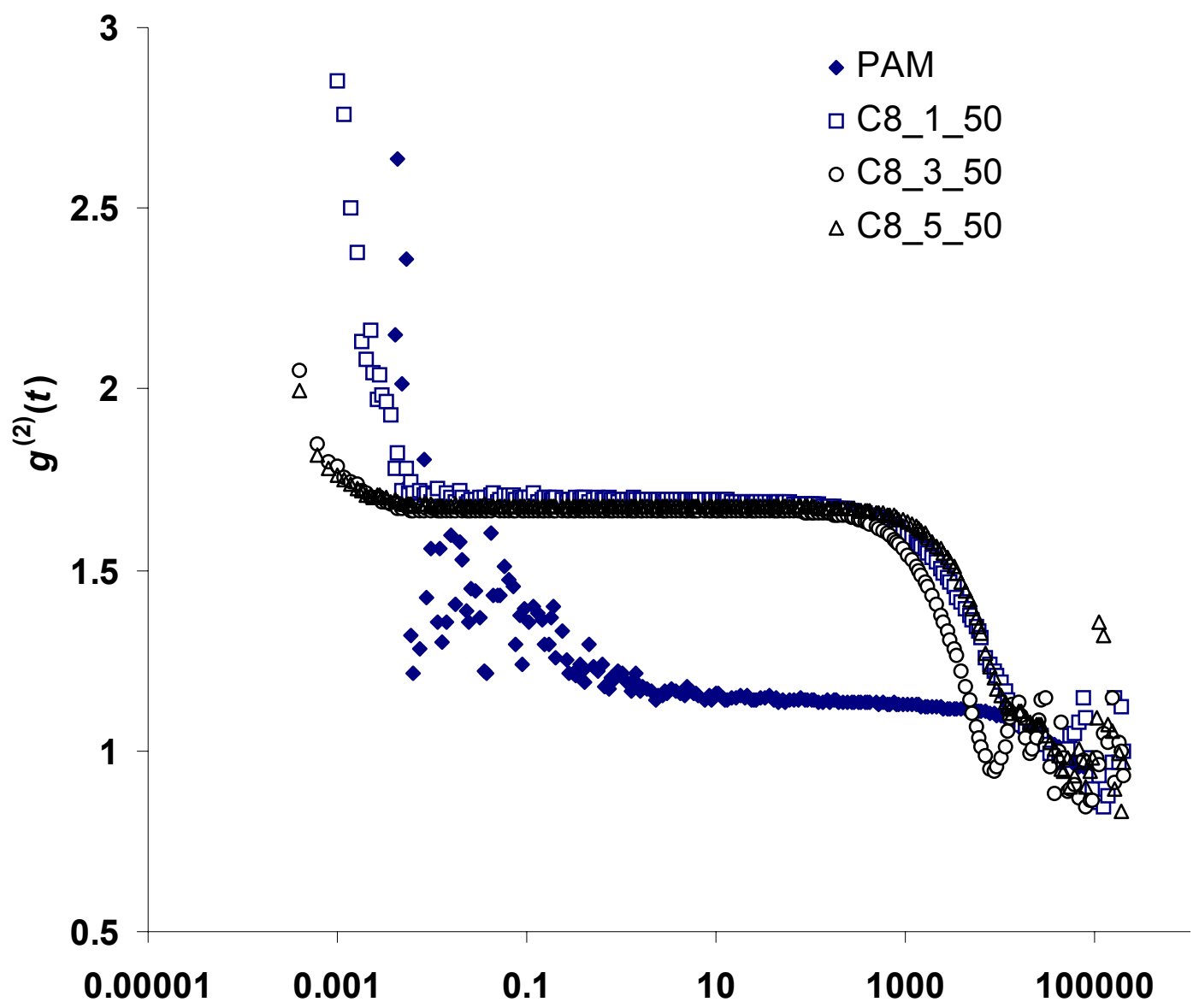

autocorrelation time

Figure 5. Autocorrelation function $g^{(2)}(t)$ of polymers at $50 \mathrm{wt} \%$. 


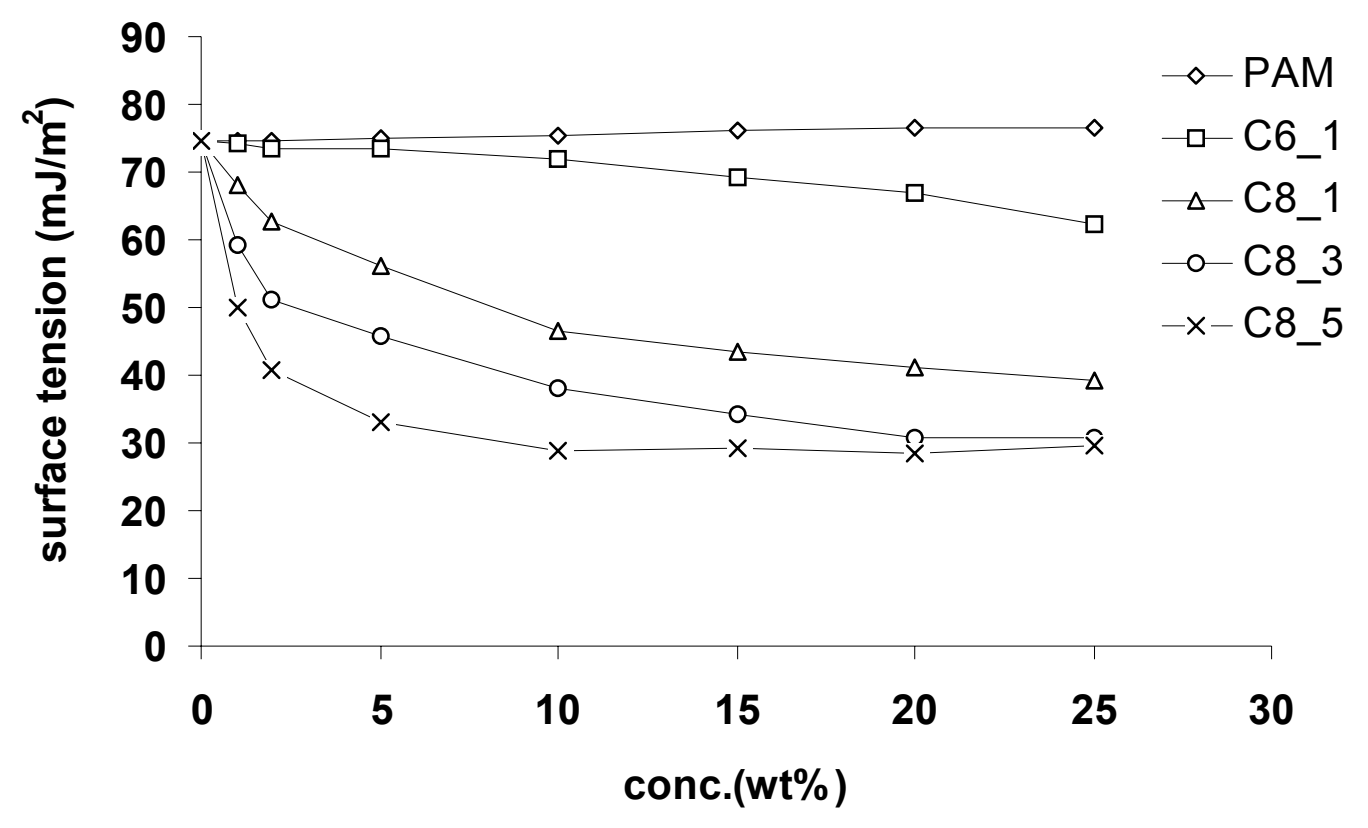

Figure 6. Surface tension $\left(\mathrm{mJ} / \mathrm{m}^{2}\right)$ versus polymer concentration $(\mathrm{wt} \%)$ in pure water solution 


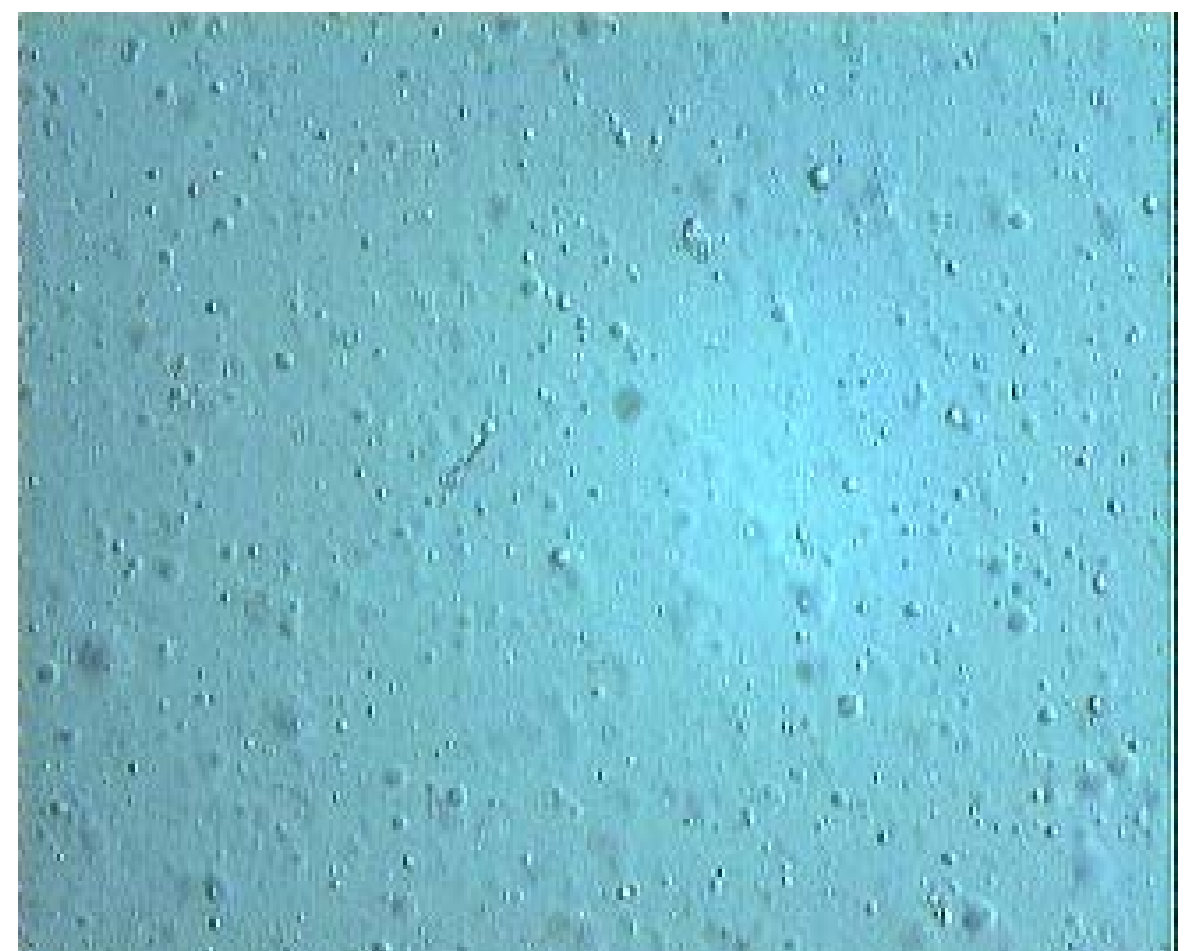

Figure 7. Photo of water-HMPAM-decane mixture (x100) 

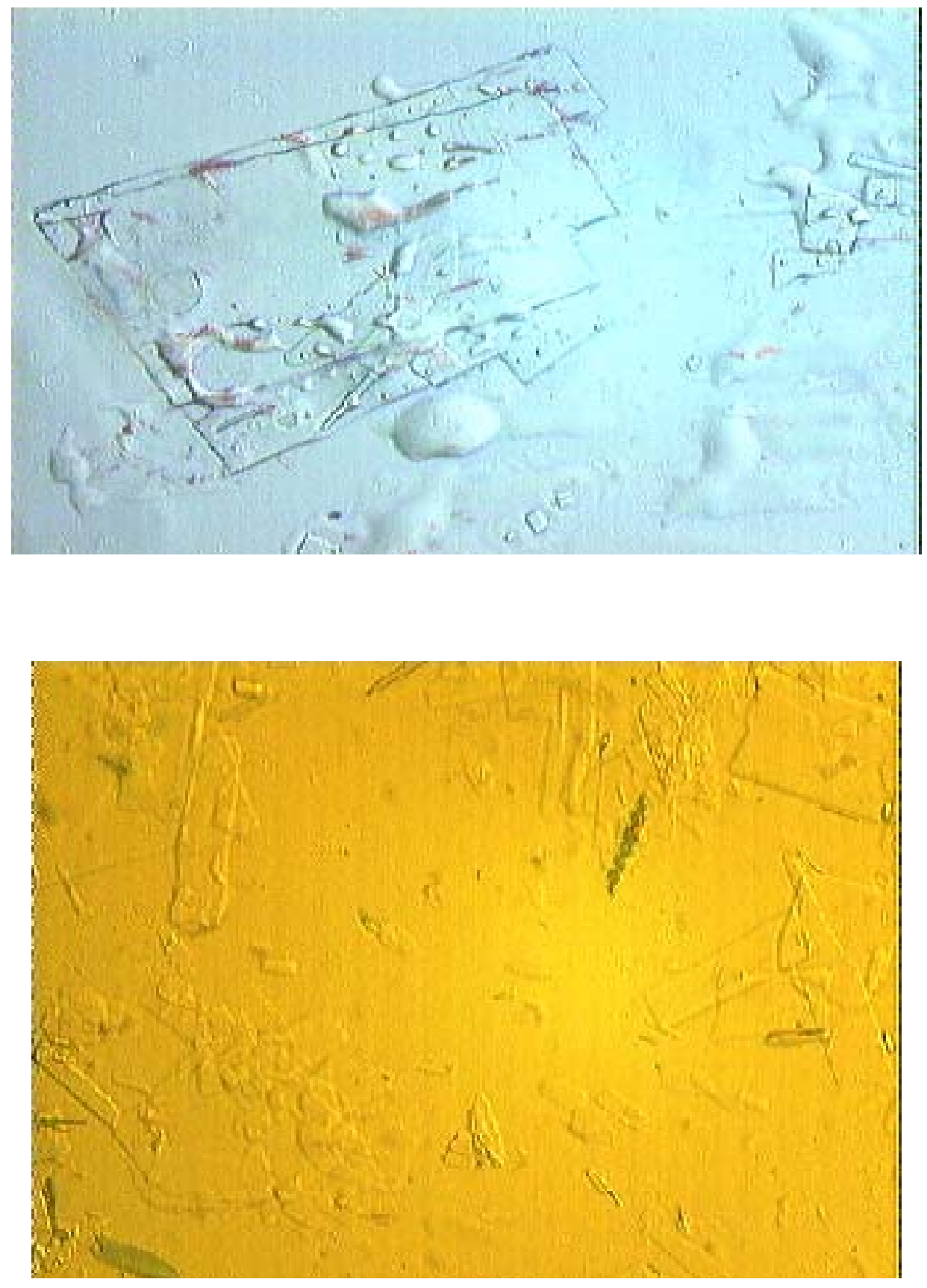

Figure 8. Photos of phase separation at HMPAM-SDS systems (x100) 


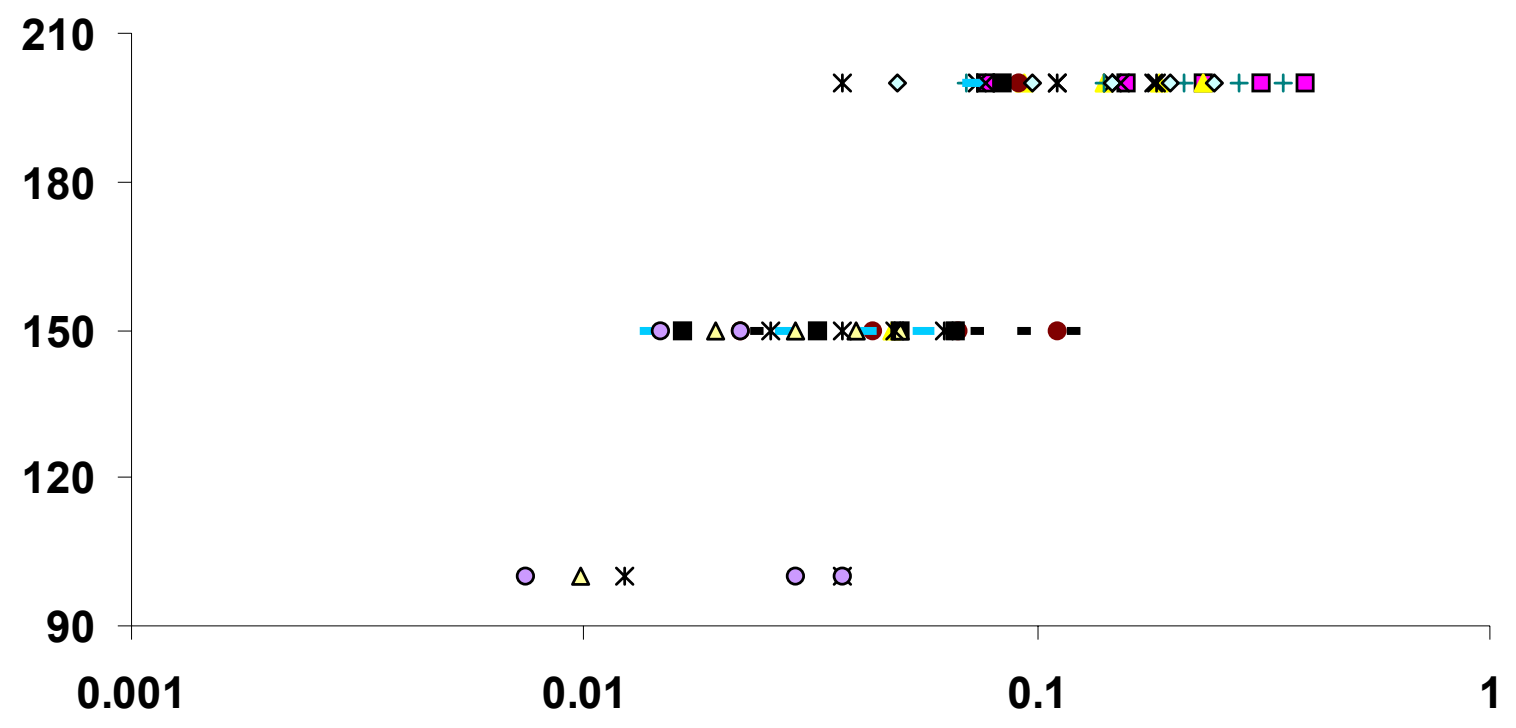

$\mathbf{N}_{\text {SDS }} / \mathbf{N}_{\mathrm{h}}$

Figure 9. Phase conditions of HMPAM-SDS systems versus value of $\mathrm{N}_{\mathrm{SDS}} / \mathrm{N}_{\mathrm{h}}(<1)$. 


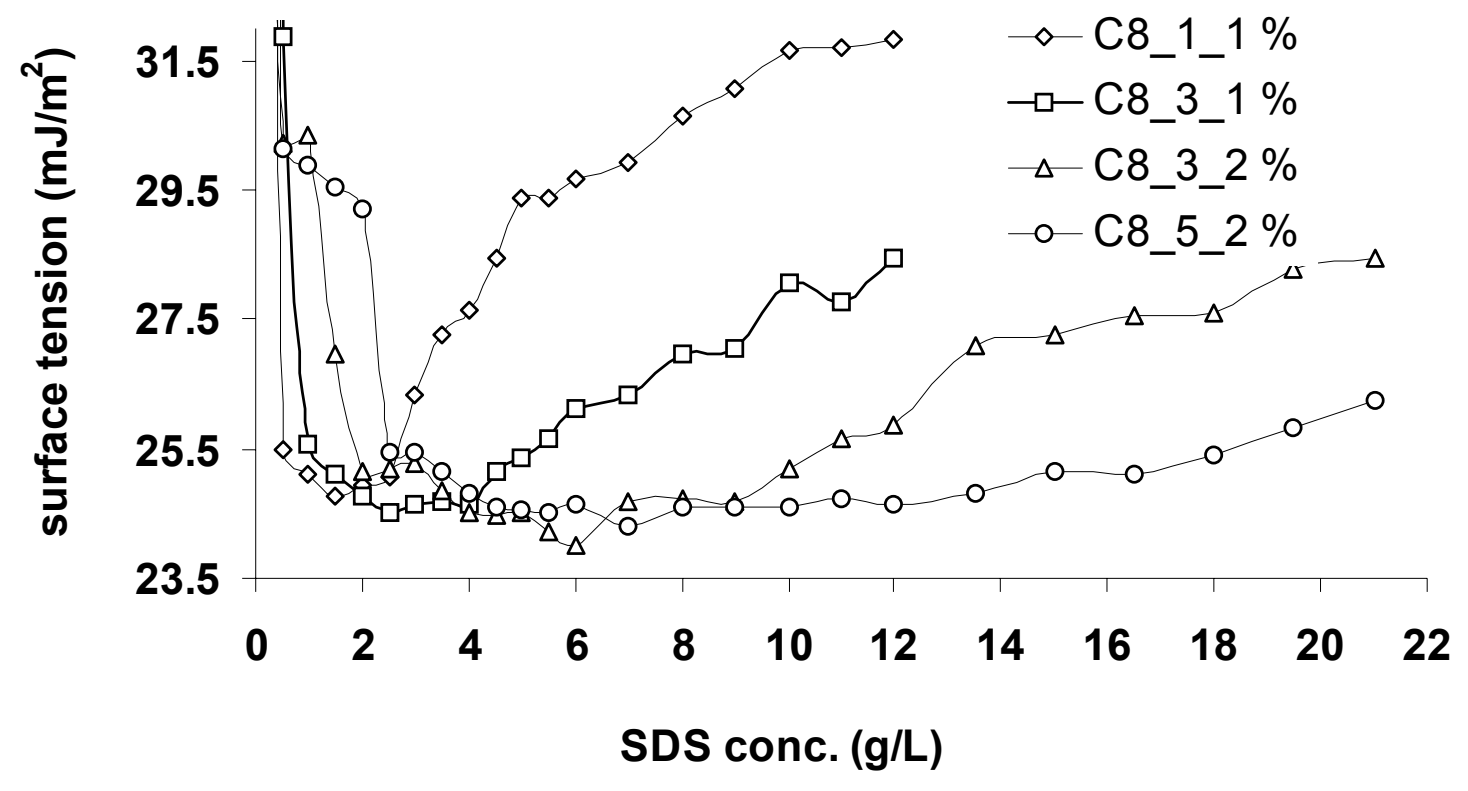

Figure 10. Surface tension $\left(\mathrm{mJ} / \mathrm{m}^{2}\right)$ of HMPAM-SDS systems versus SDS concentration $(\mathrm{g} / \mathrm{L})$ 


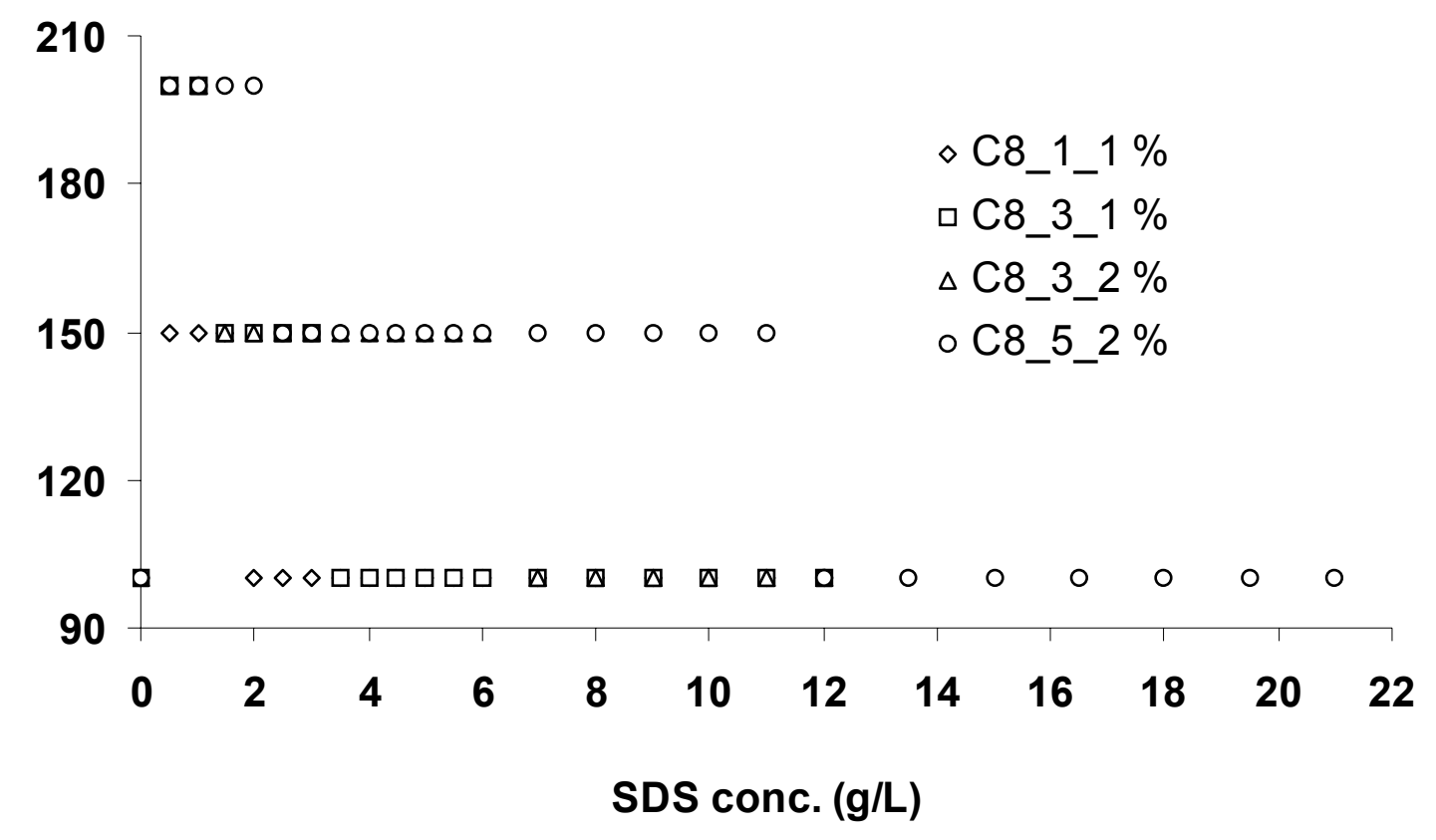

Figure 11. Phase conditions of HMPAM-SDS systems versus SDS concentration (g/L) 


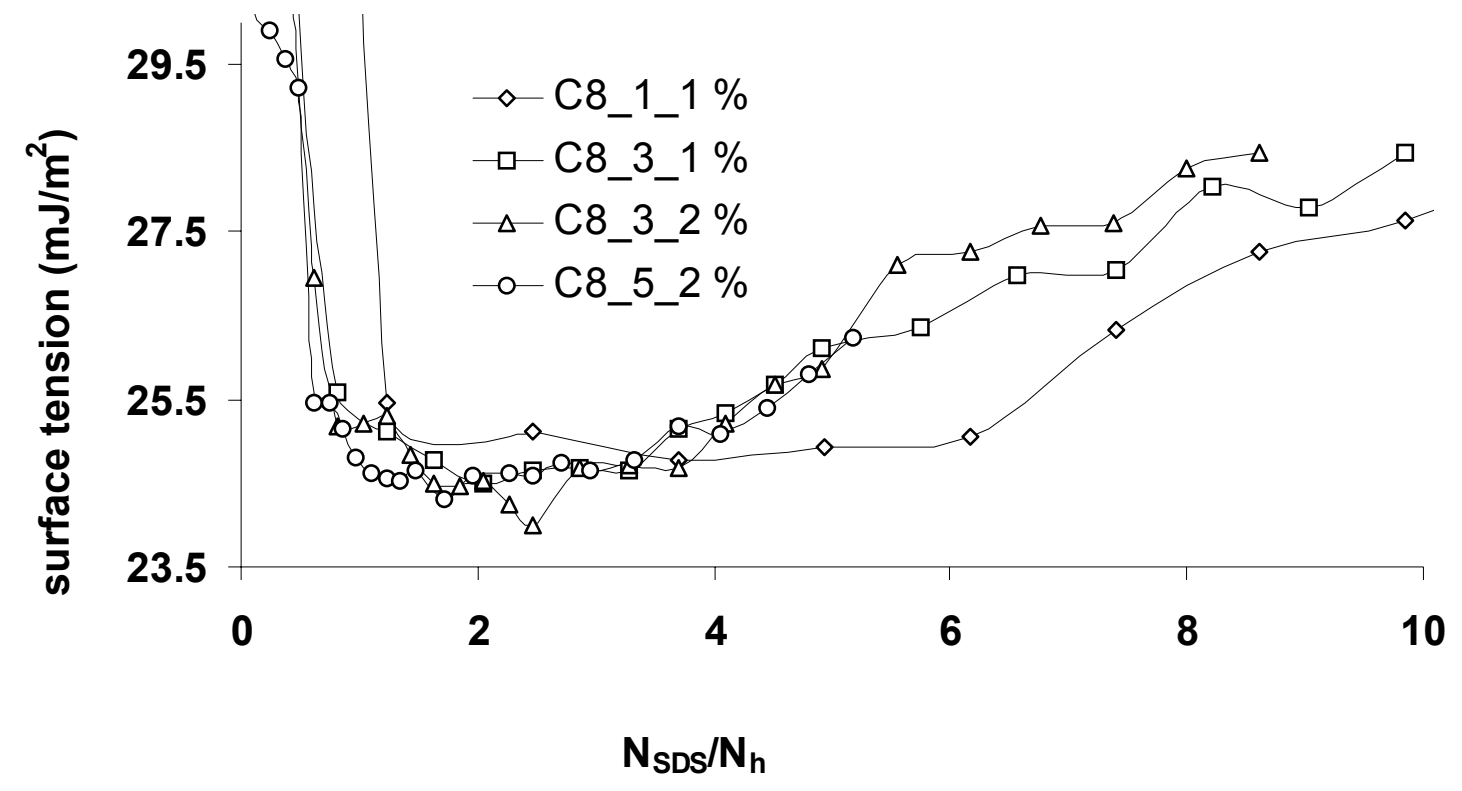

Figure 12. Surface tension $\left(\mathrm{mJ} / \mathrm{m}^{2}\right)$ of HMPAM-SDS systems versus value of $\mathrm{N}_{\mathrm{SDS}} / \mathrm{N}_{\mathrm{h}}(>1)$ 


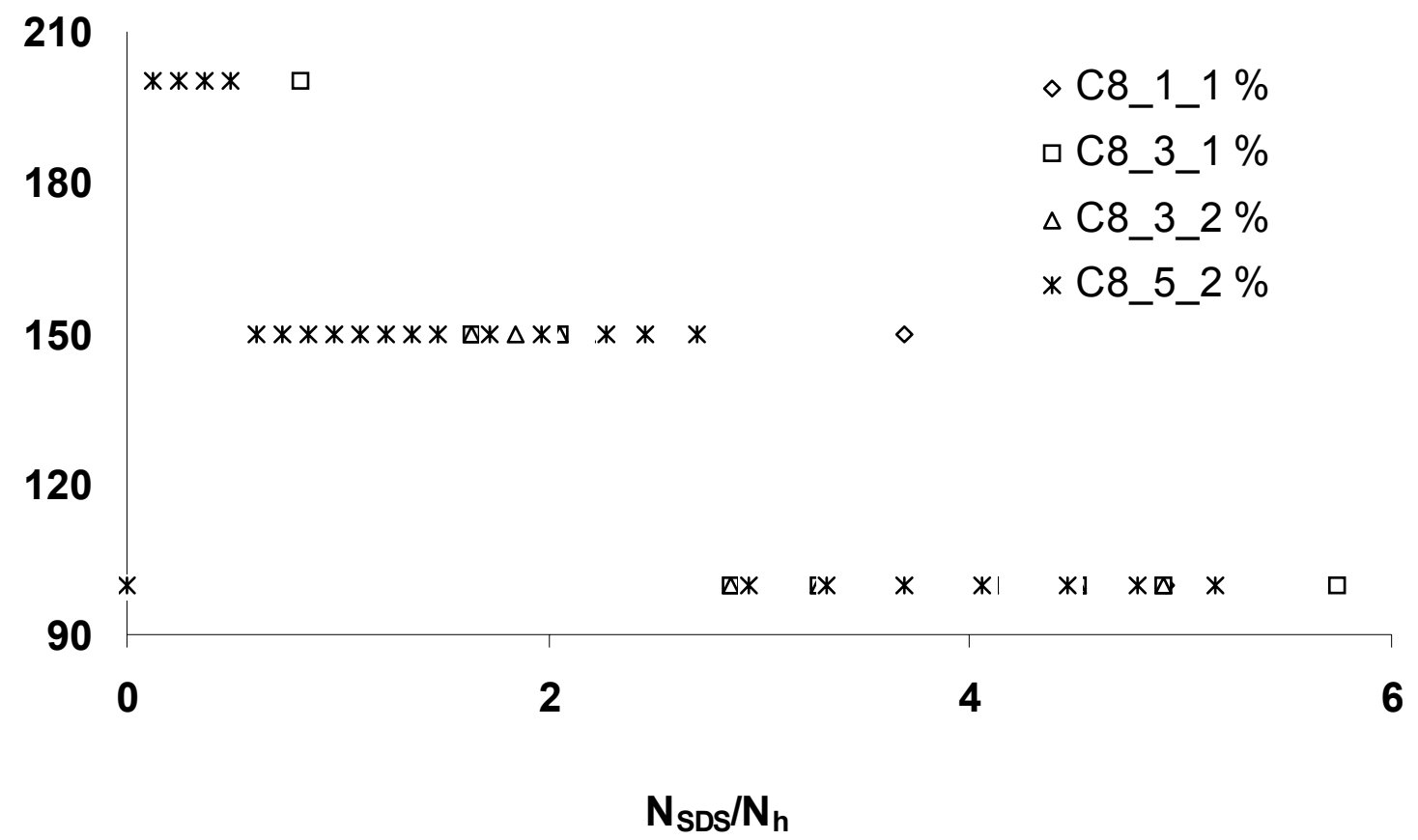

Figure 13. Phase conditions of HMPAM-SDS systems versus value of $\mathrm{N}_{\mathrm{SDS}} / \mathrm{N}_{\mathrm{h}}(>1)$ 